\title{
تصوف واصطاراتِ تصوف \\ An Analytical Study of Mysticism and its Terminologies
}

\author{
Dr. Syed Atta Üllā'h Bukhärì \\ Lecturer in Islāmic Studies, Cadet College Ghotkī, Sindh, Pakistan \\ Email:syedatta4@gmail.com
}

\section{Dr. Häfiz Munìr Ahmed Khän}

Dean Faculty of Islämic Studies University of Sindh, Jamshoro, Pakistan Email: hafiz.munir@usindh.edu.pk

\begin{abstract}
:
Mysticism is an erea of knowledge, which purifies bodies, ethics and soul. Mysticism is based on soul. Man is composed of body and soul thus the importance of soul is static. To purify the soul it is essential to have knowledge of the Qurā'n and Hadith. A person knows well the Qurä'n and Hadith is called a mystic or a scholar of mysticism. Knowledge and mysticism are the best source to get closer to Allāh Almighty. Through this experience a person can reach the highest degree of spirtuality. All the secrets of universe are disclosed to him with this sort of knowledge, so the Mysticism is the soul of Islam and a fact of religion. It teaches love with human beings and religions as well as ethics, peace, brotherhood, unity and patriotism. The purpose of this article is to highlight the role of mysticism and mystics in imparting Islämic education in our society for the revival of Isläm and it culture.
\end{abstract}

Keywords: Mysticism, Mystics, Religion, Revive, Spirtuality

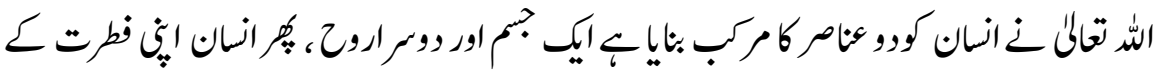

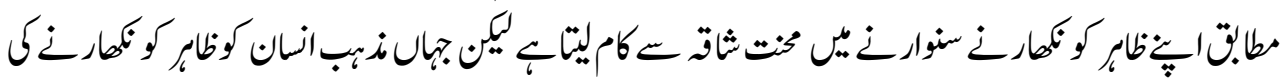

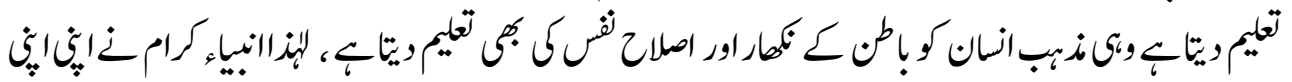

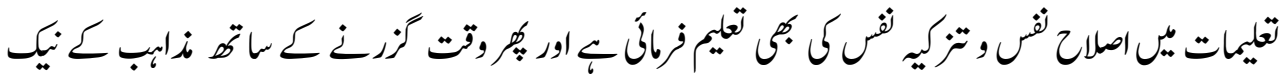

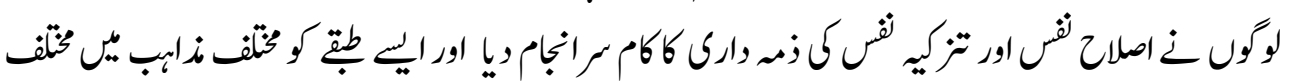

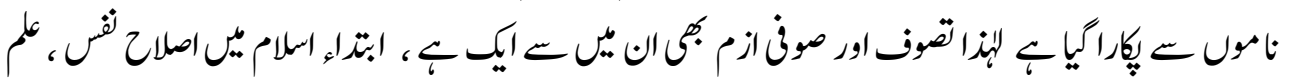

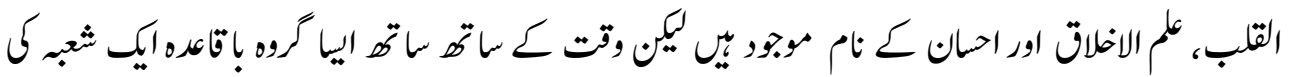

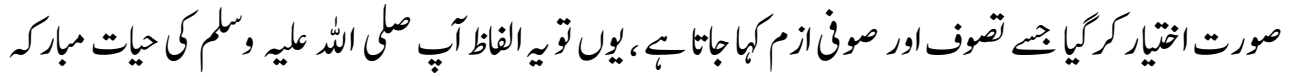

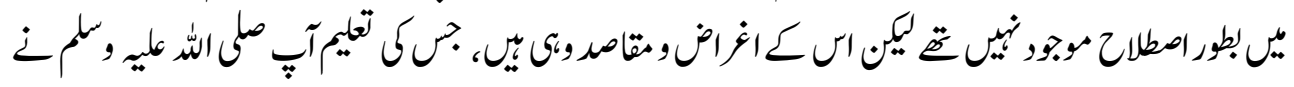




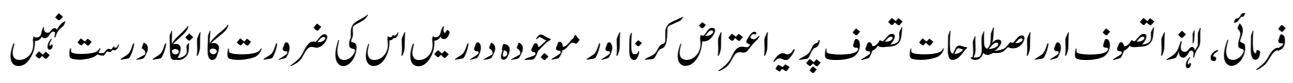

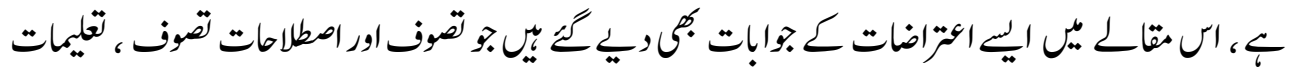

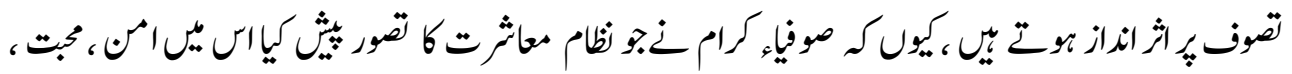

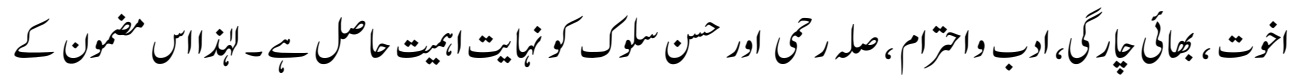

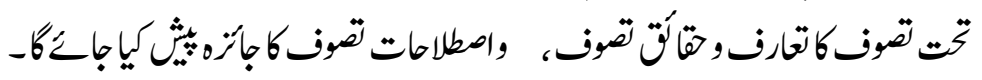
صوف كياء؟

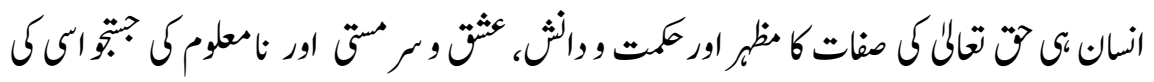

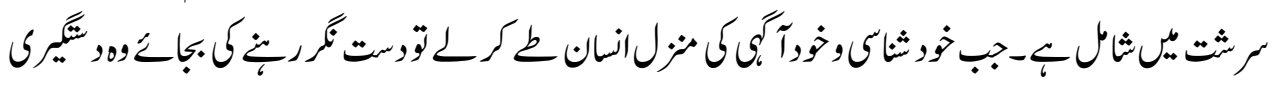

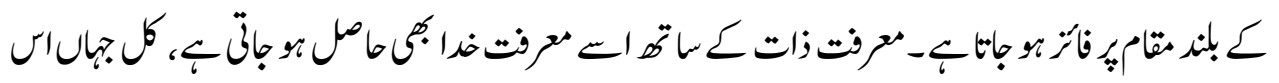

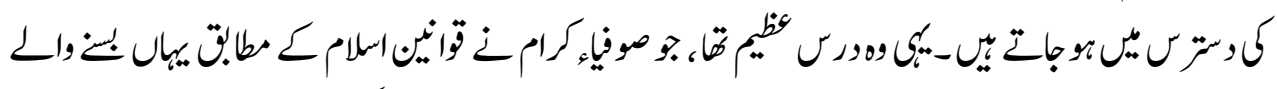

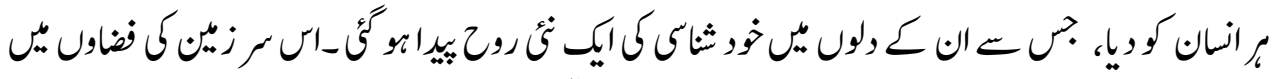

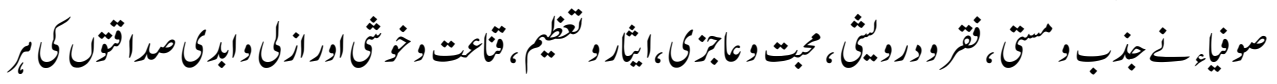

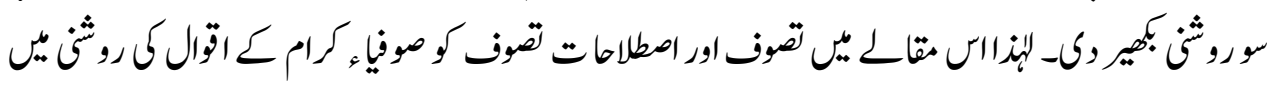

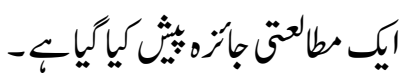

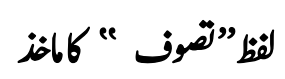

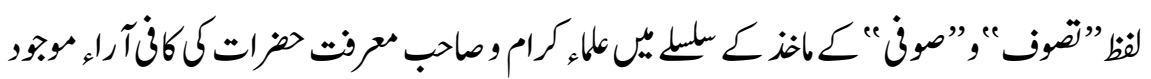

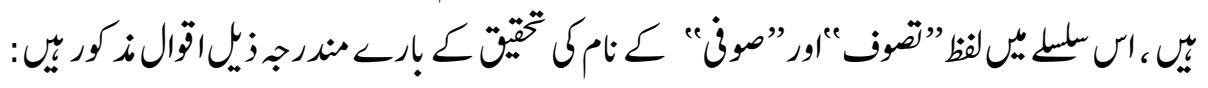
(1)

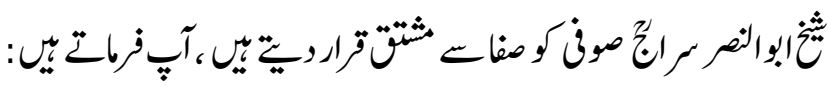

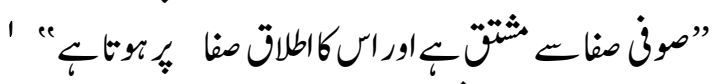

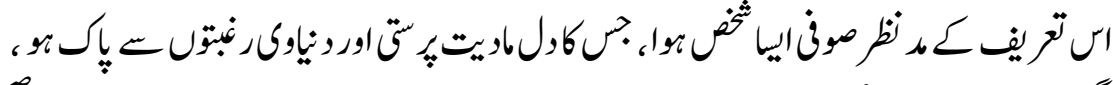

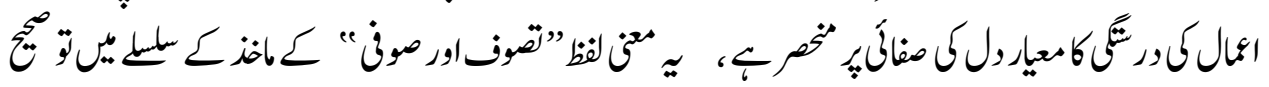

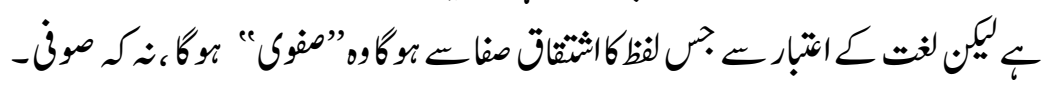

صوف:

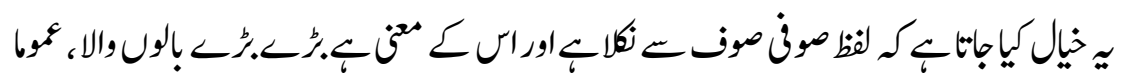

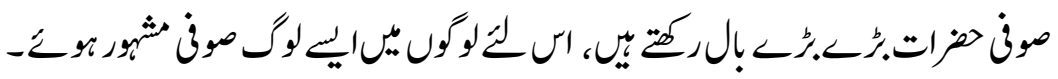


$[r \cdot]$

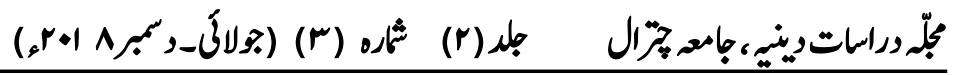

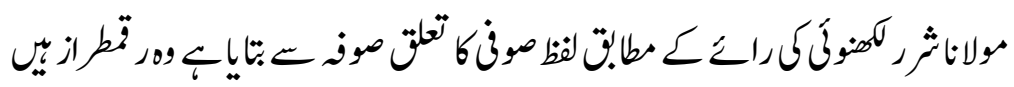

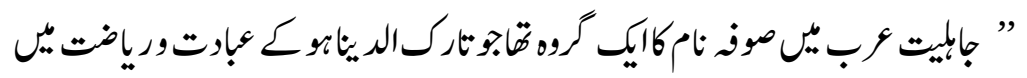

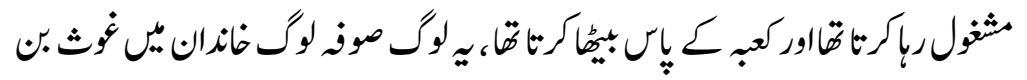

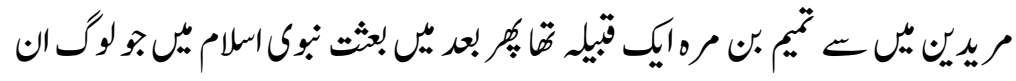

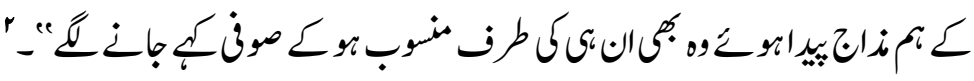

: (r)

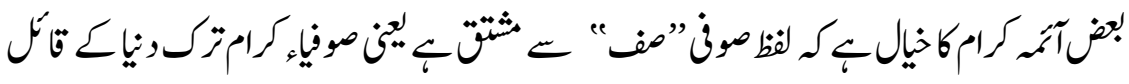

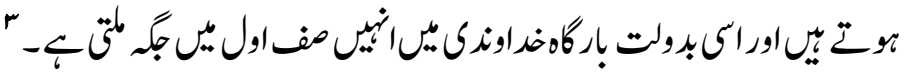

ثماسون:

$(\Delta)$

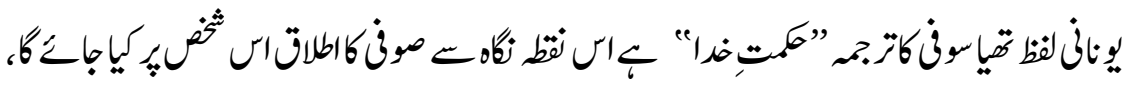

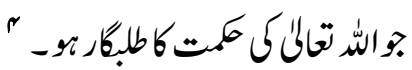

(Y)

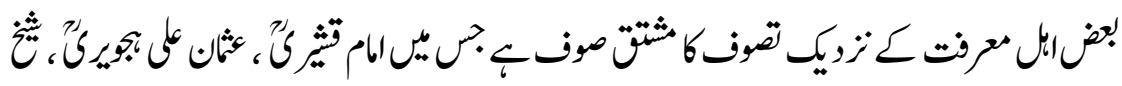

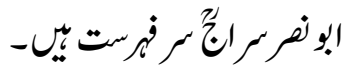

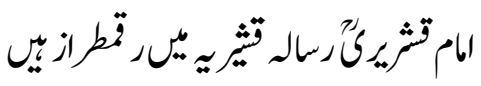

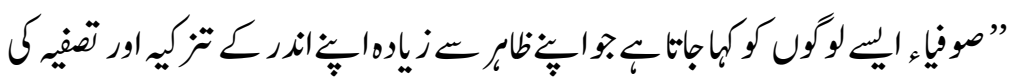

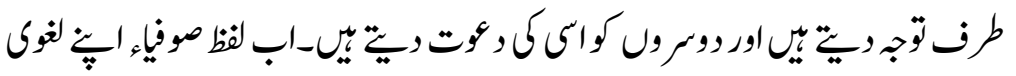

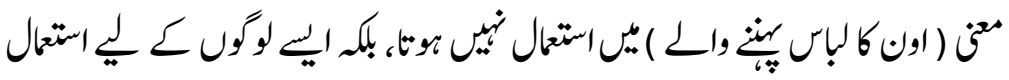

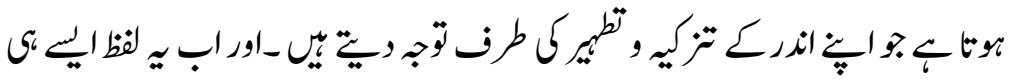

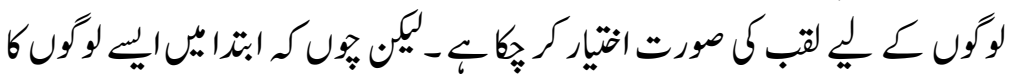

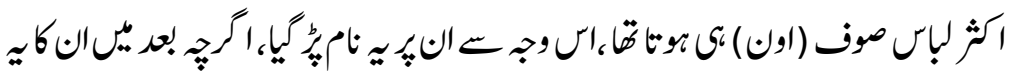

- ¿"?

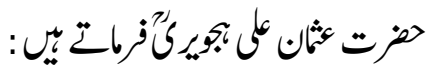

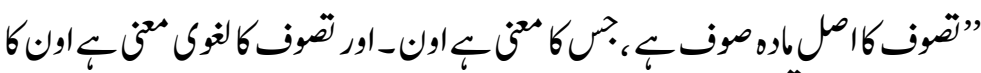

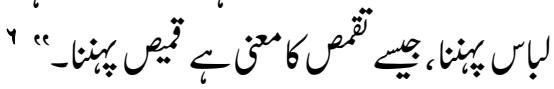

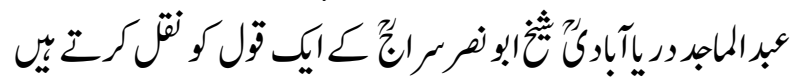


[N]

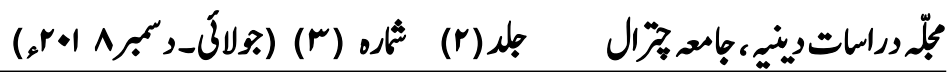

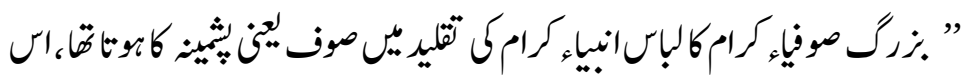

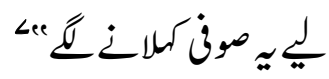

نتيج بكث:

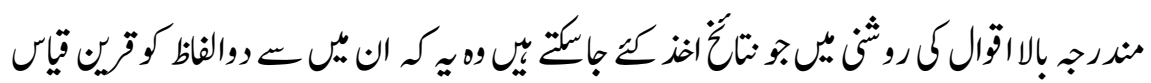

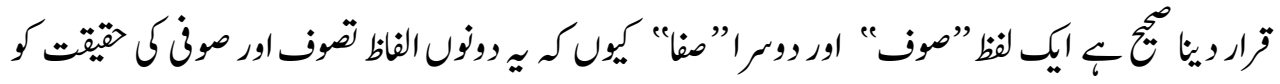

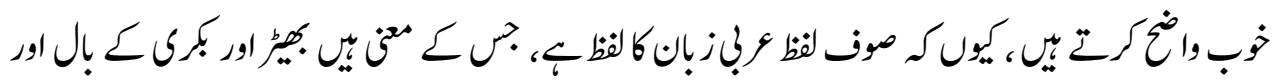

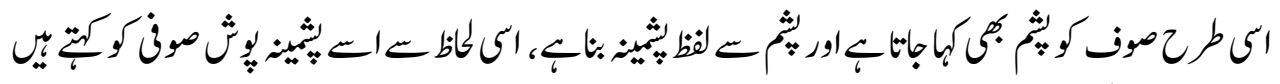

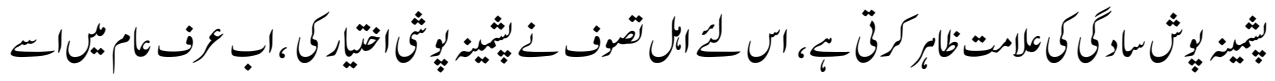

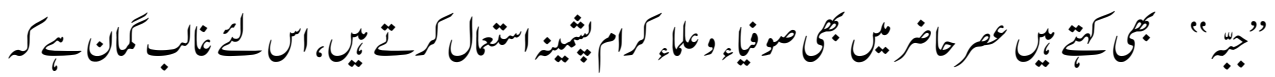

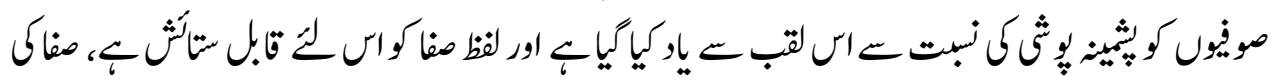

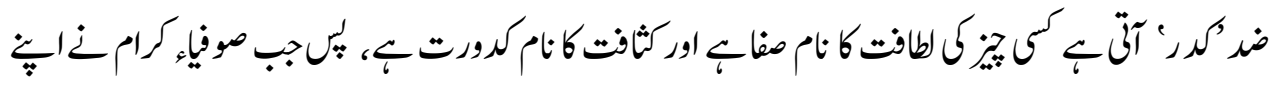

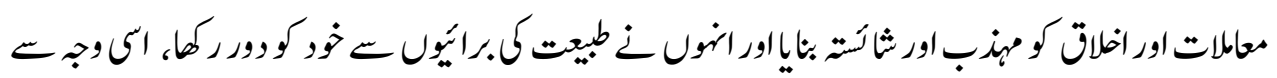

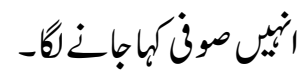
تأقت تصوف/ور اصطلاق منهوم:

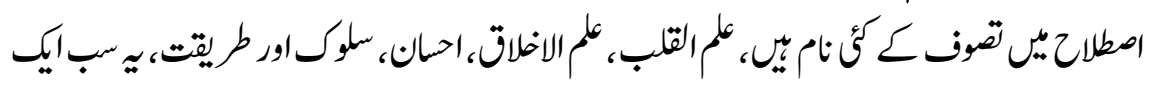

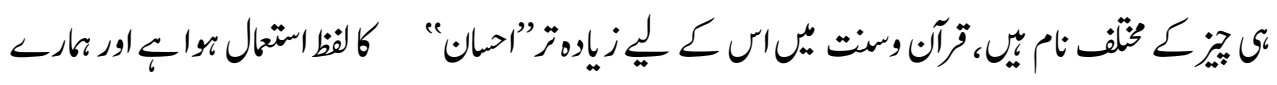

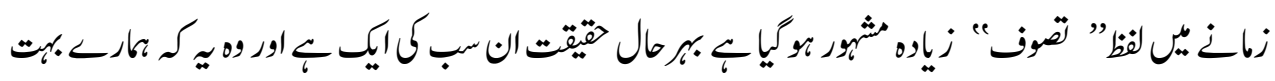

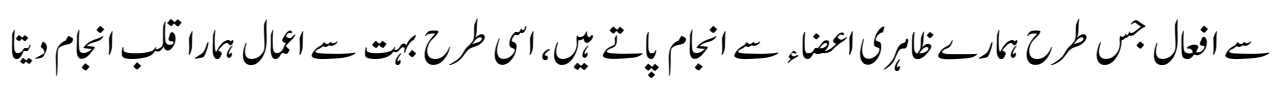

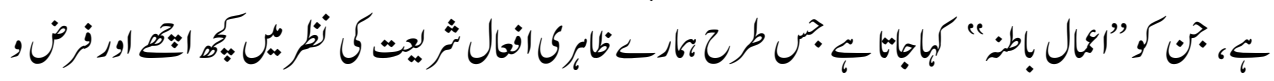

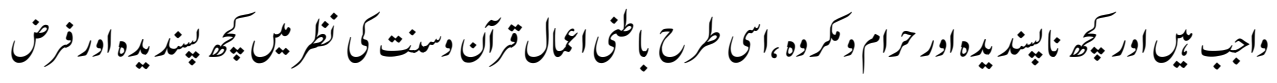

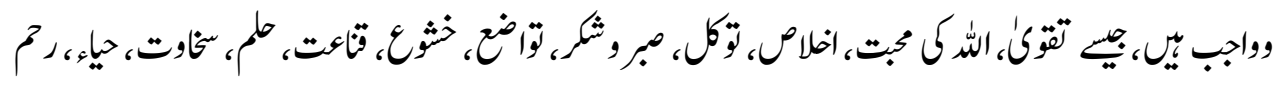

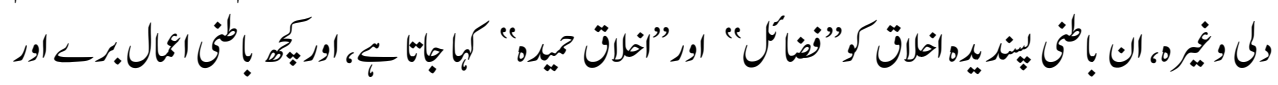

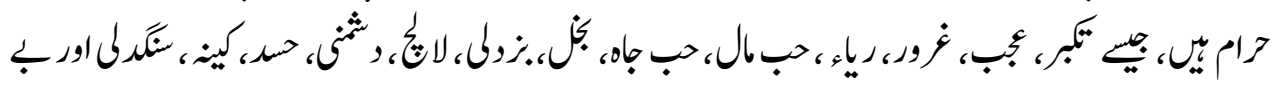

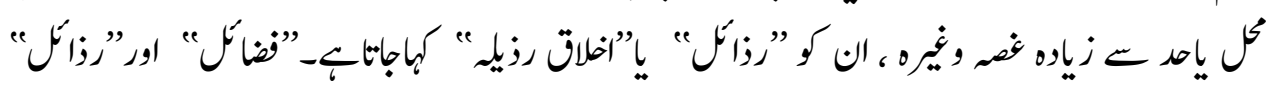

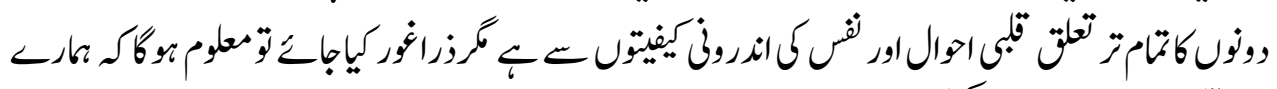

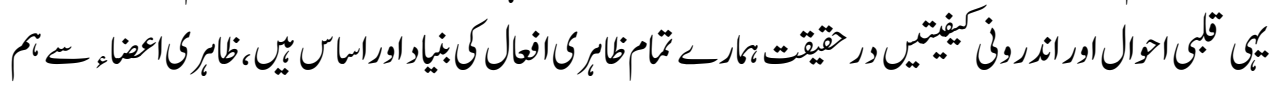

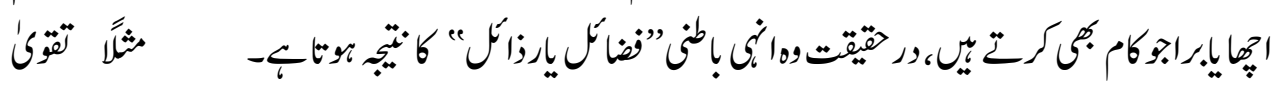




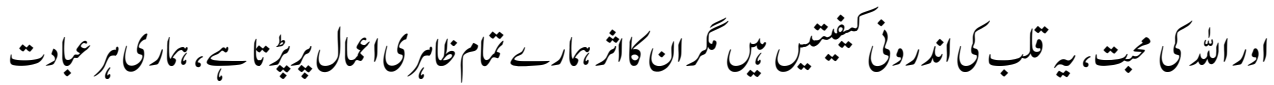

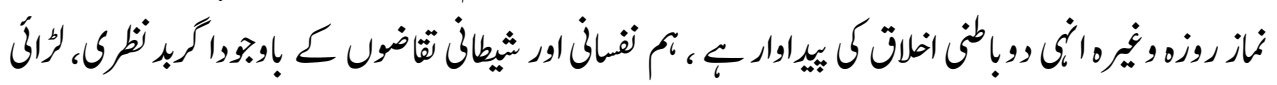

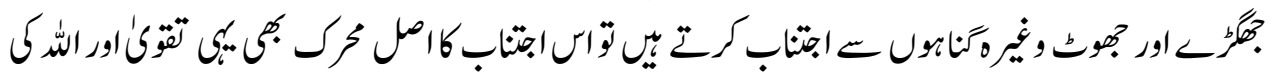

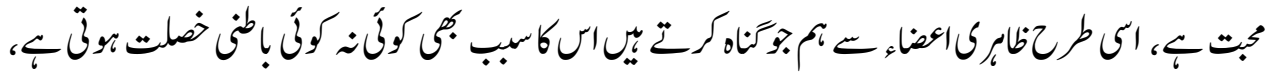

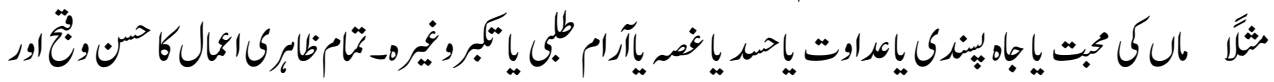

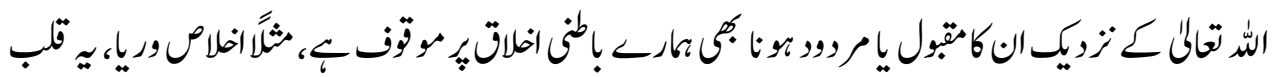

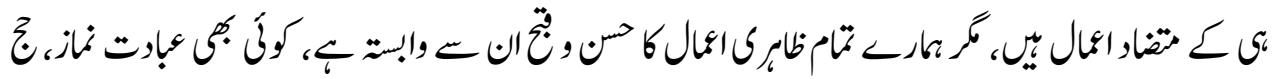

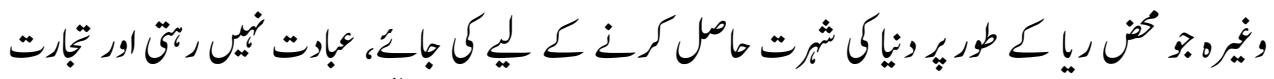

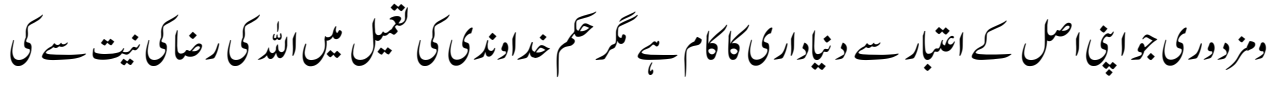

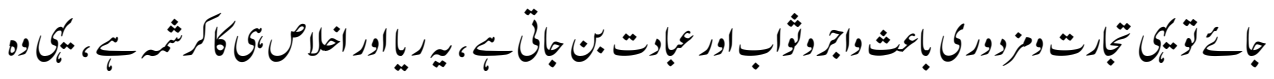

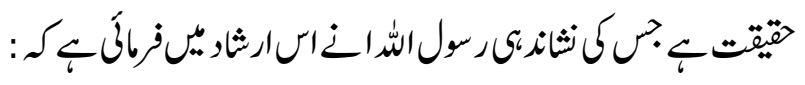

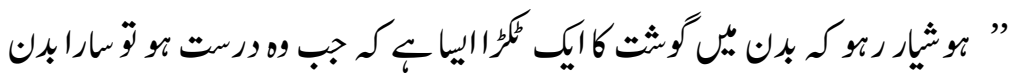

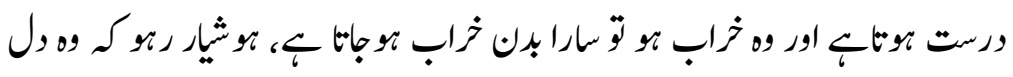
see $-c$

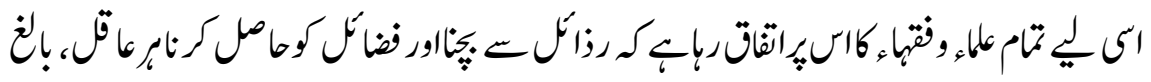

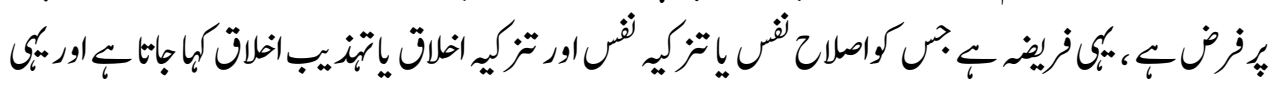

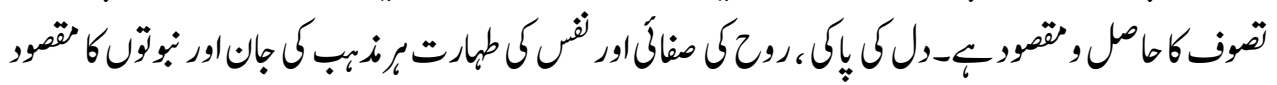

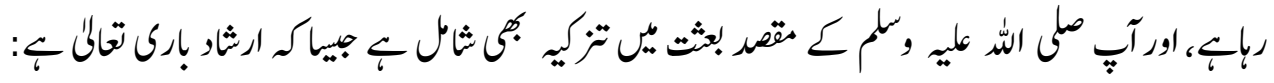

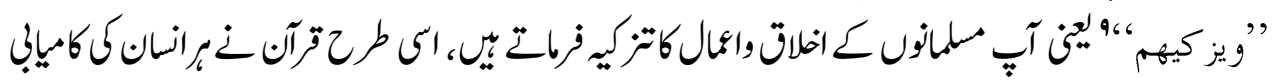

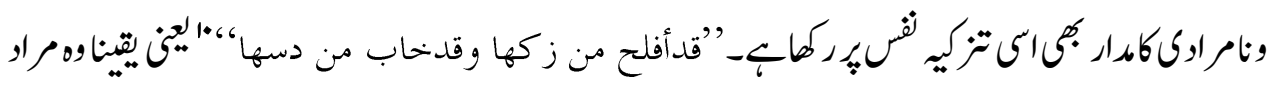

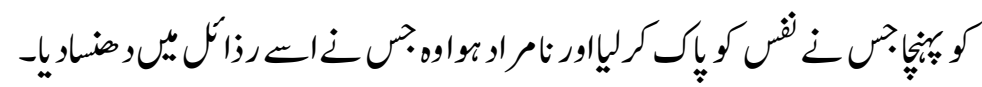

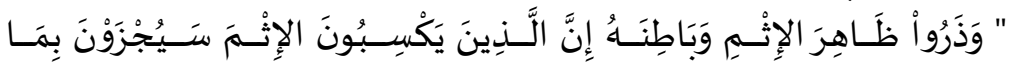

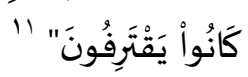

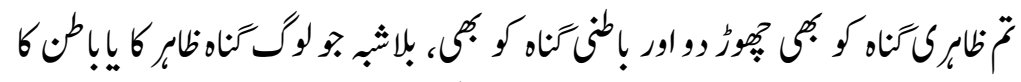

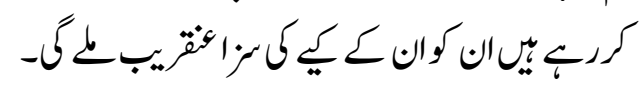

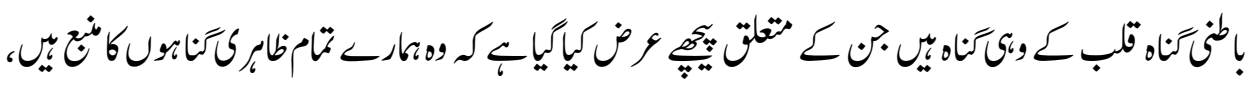

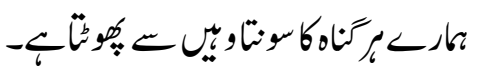


[rr]

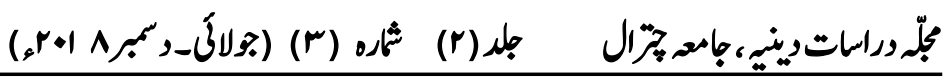

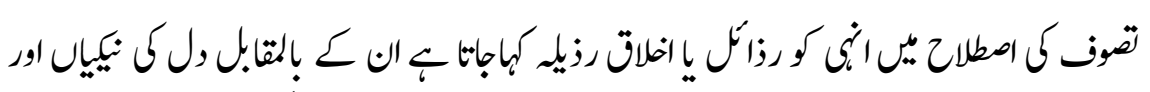

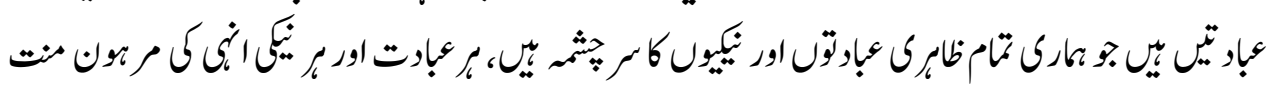

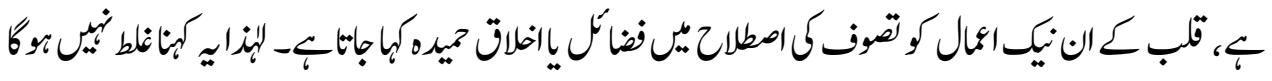

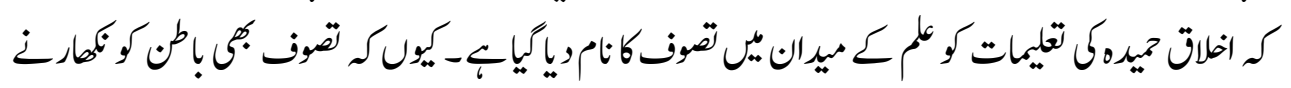

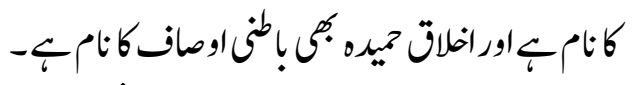

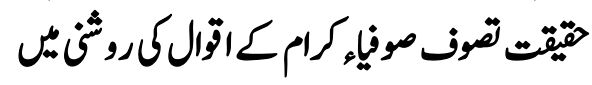

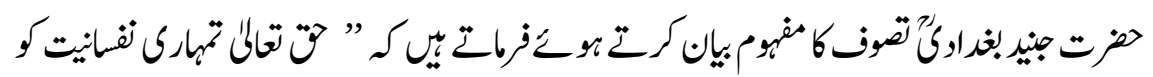

(1)

" ree

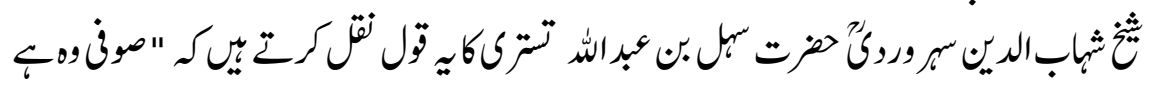

(r)

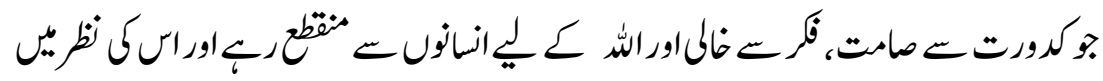

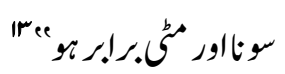

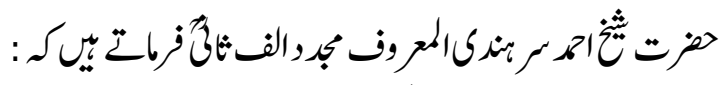

$(r)$

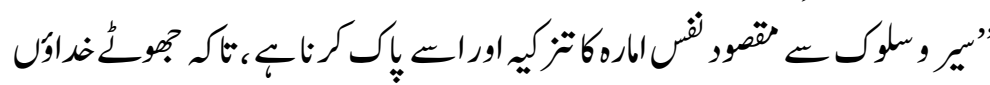

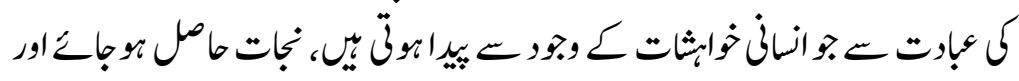

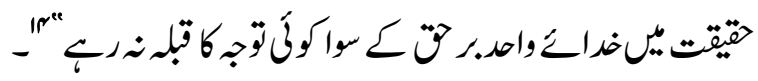

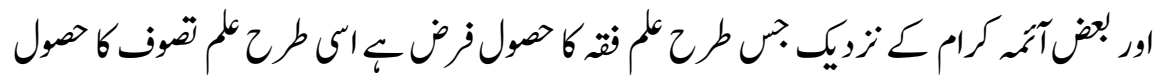

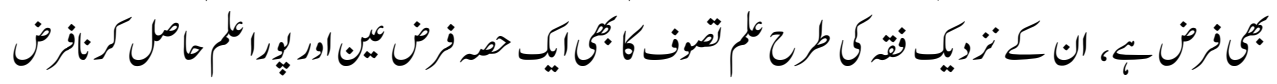

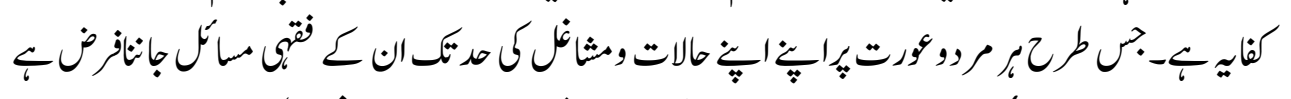

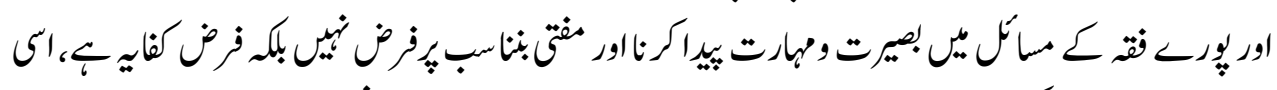

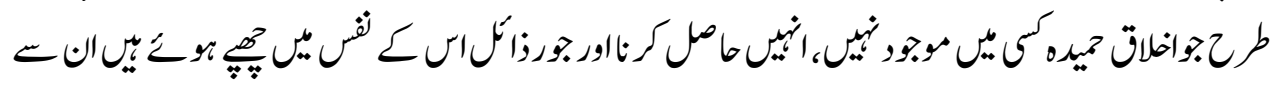

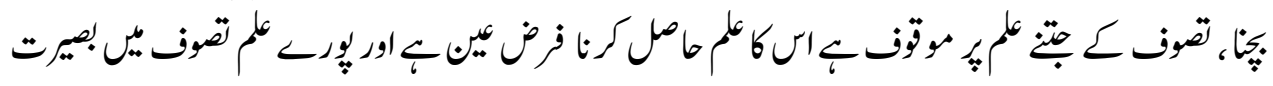

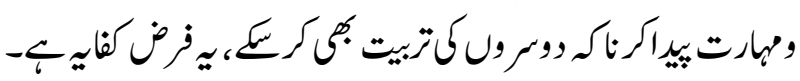

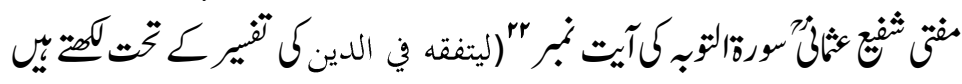

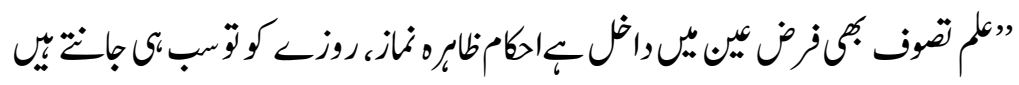

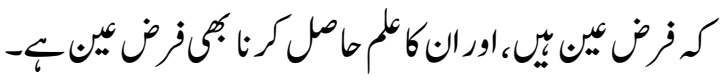


$[\mathrm{re}]$

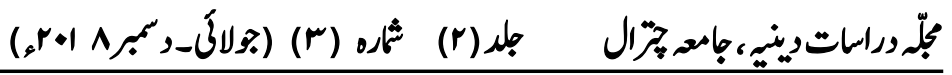

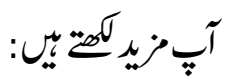

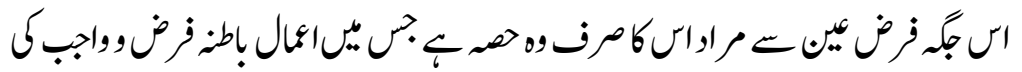

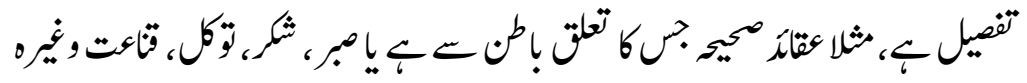

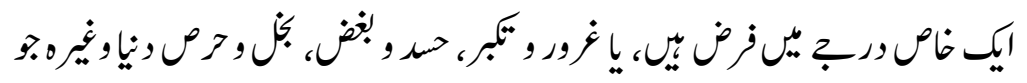

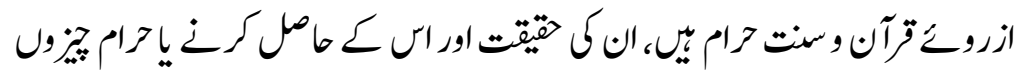

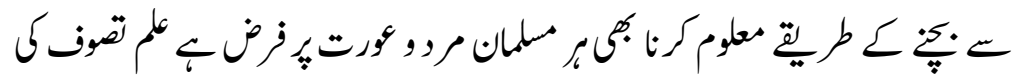

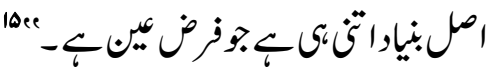

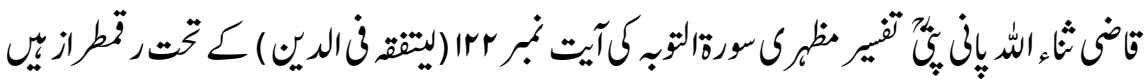

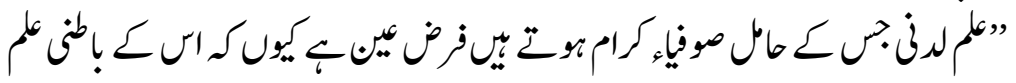

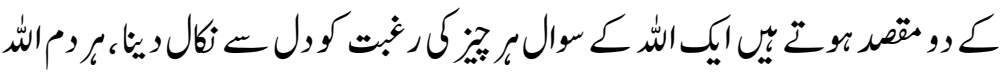

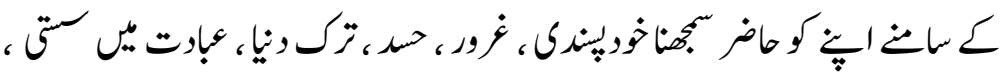

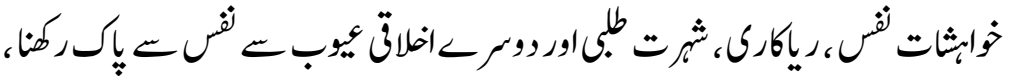

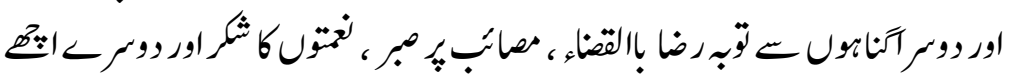

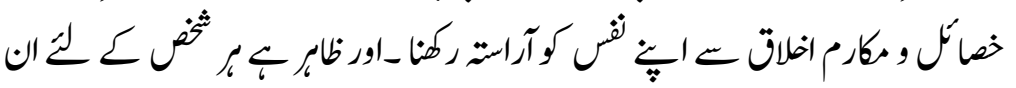

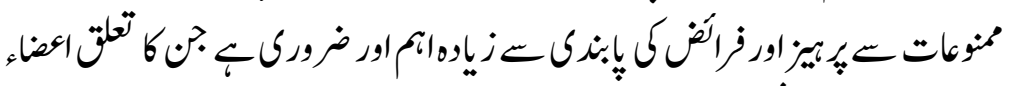

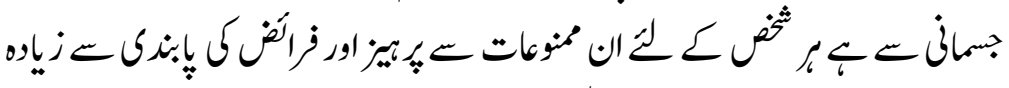

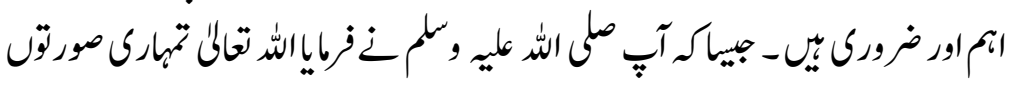

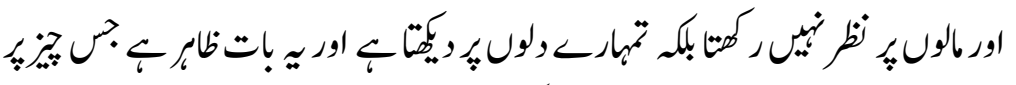

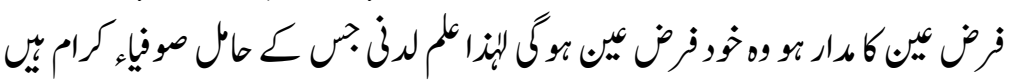

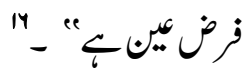

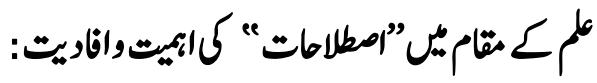

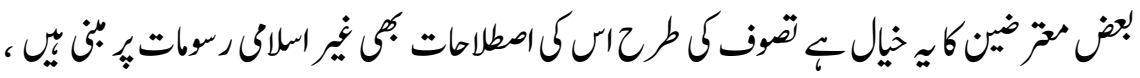

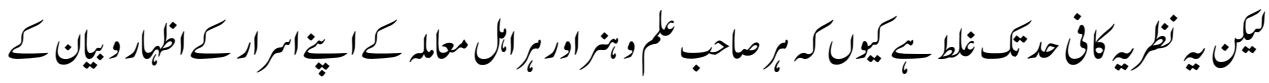

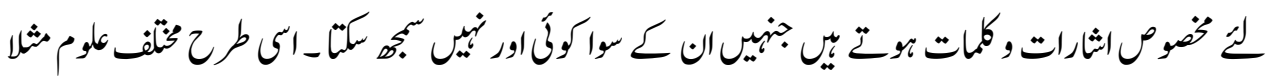

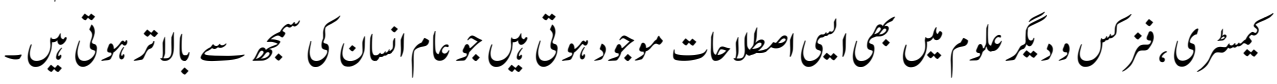

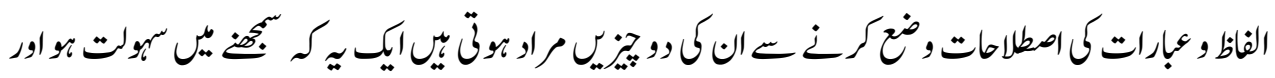

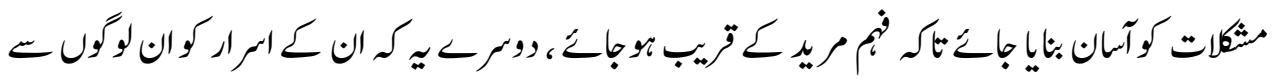


$[r \Delta]$

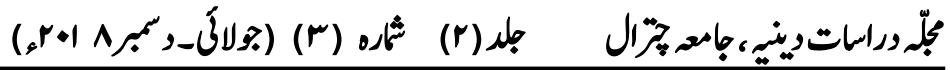

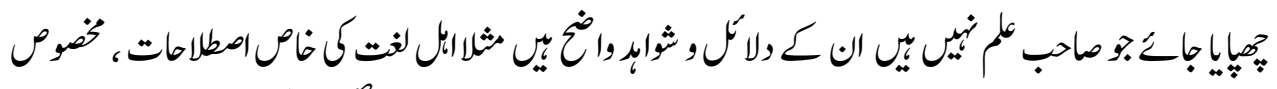

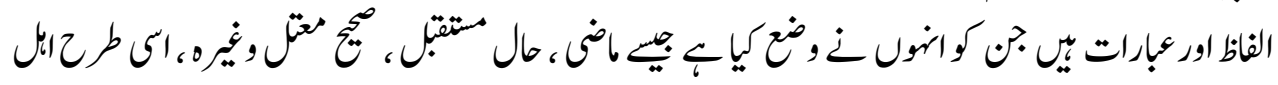

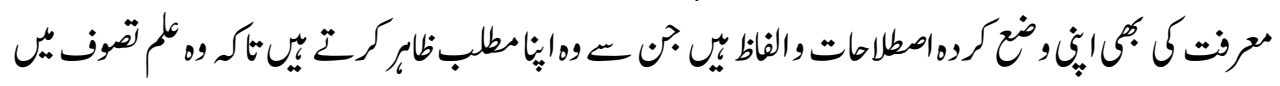

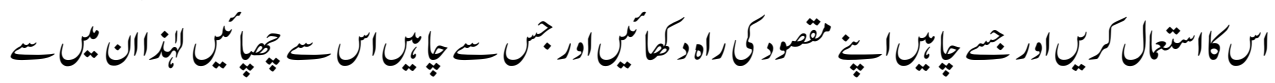

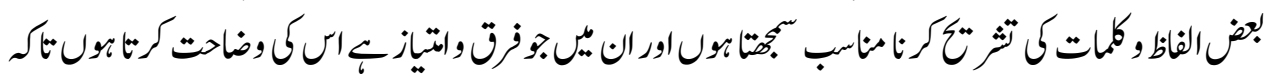

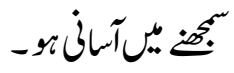

مال/م:ام:

(1)

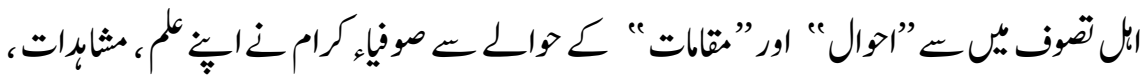

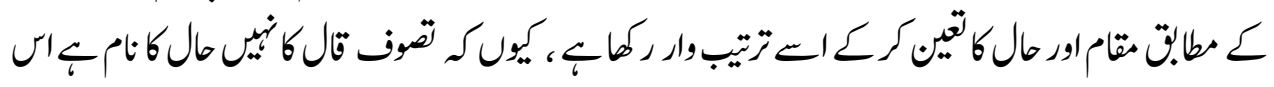

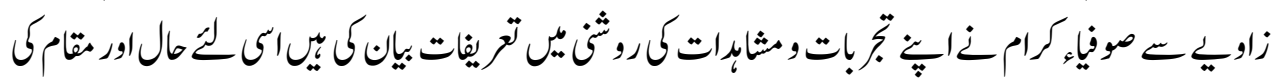

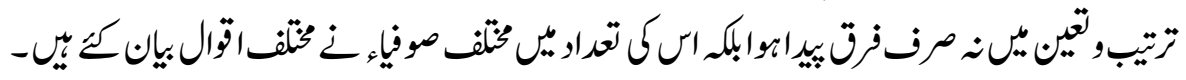

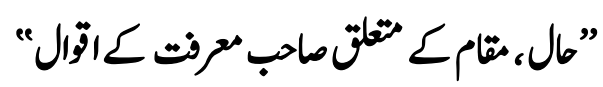

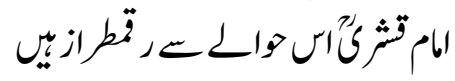

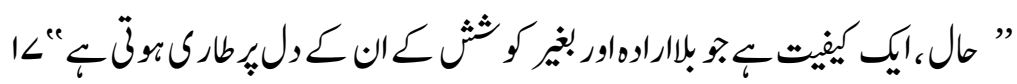

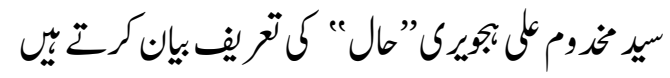

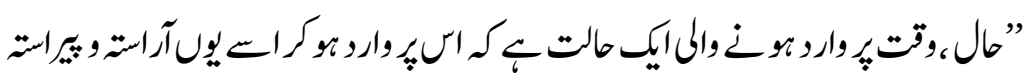

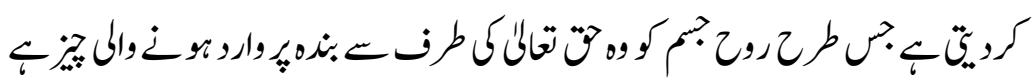

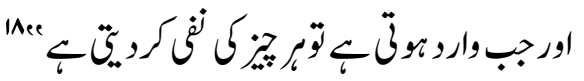

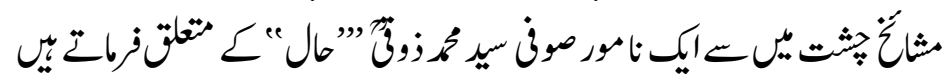

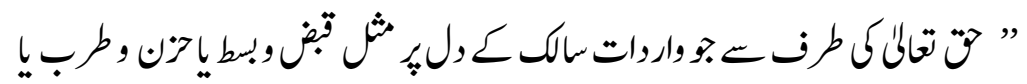

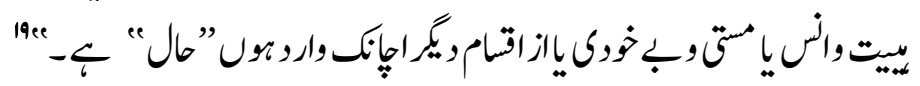

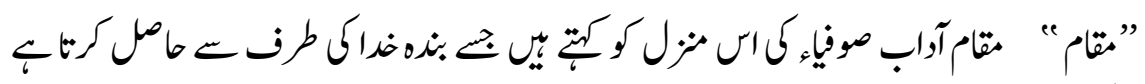

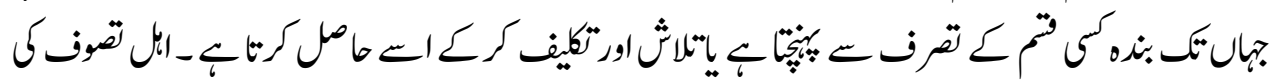

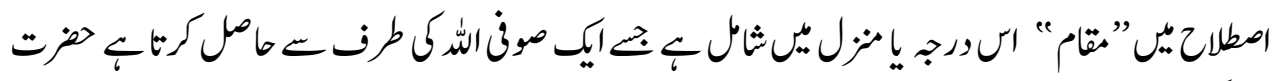

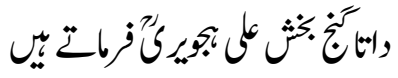

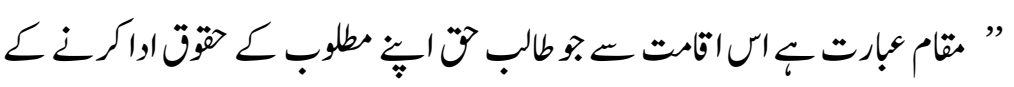

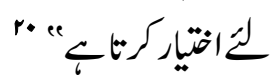


[ry]

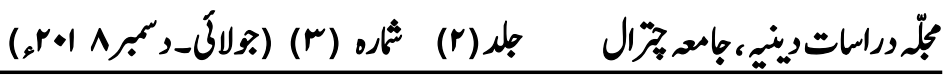

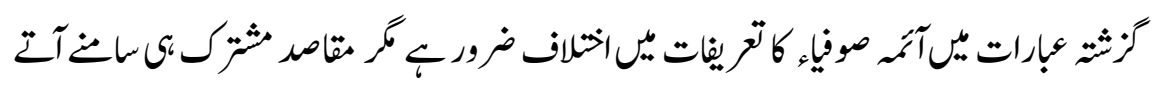

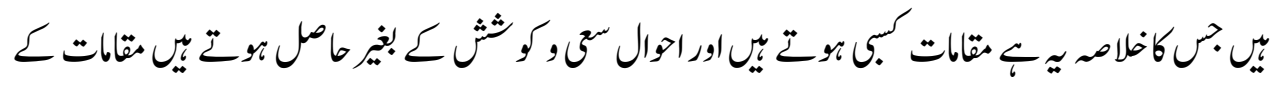

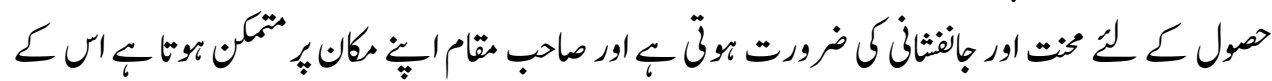

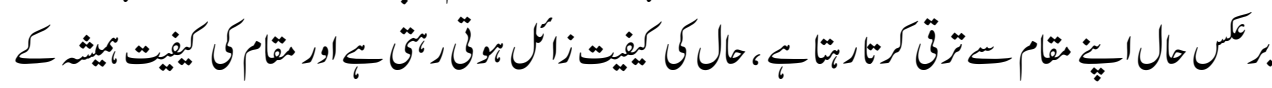

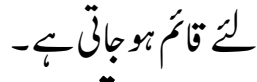

(")

(r)

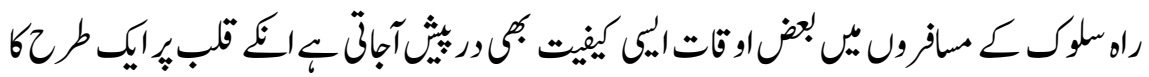

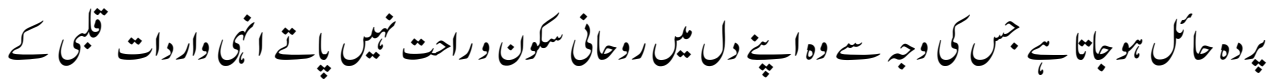

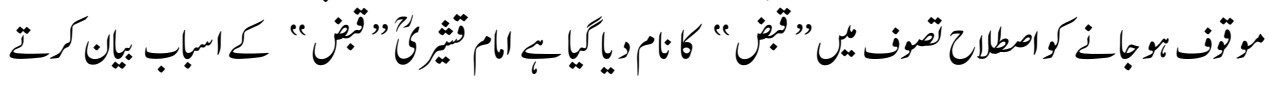

بو

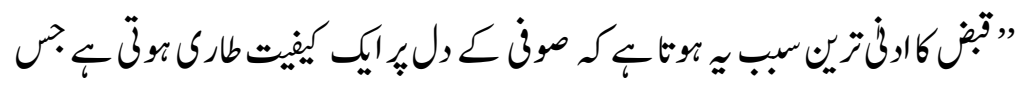

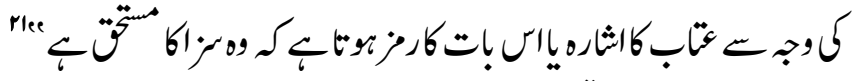

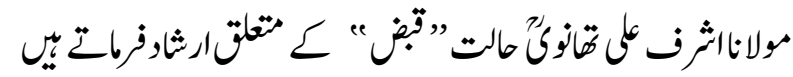

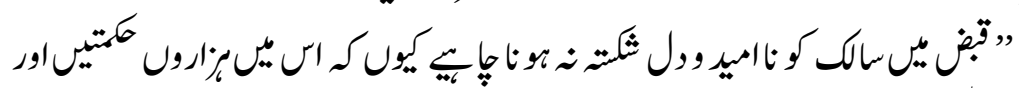

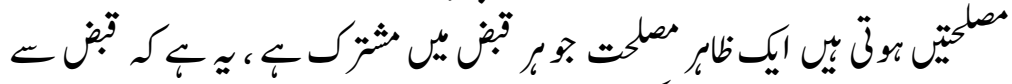

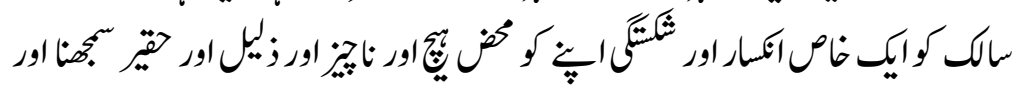

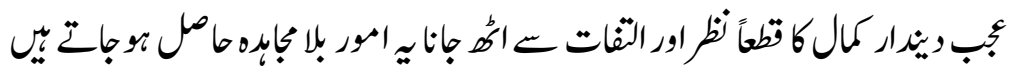

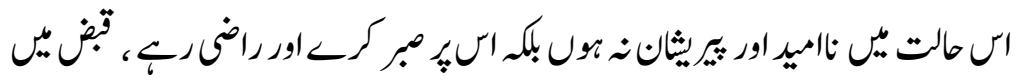

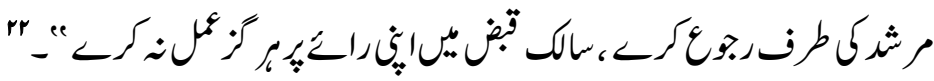

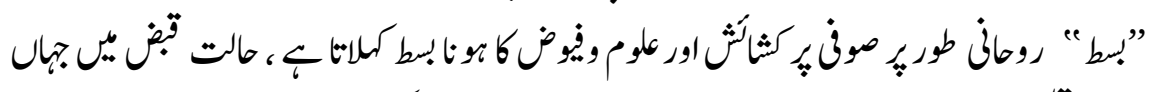

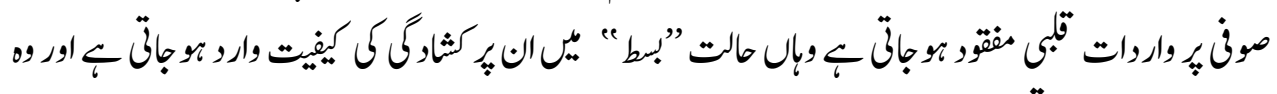

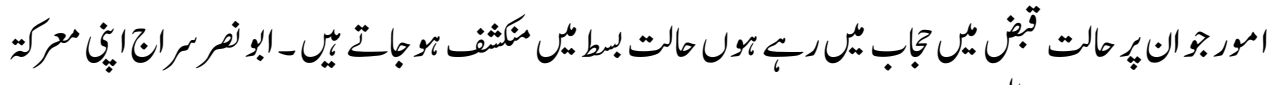

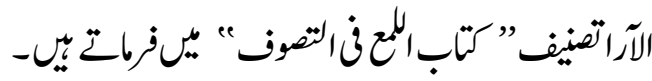

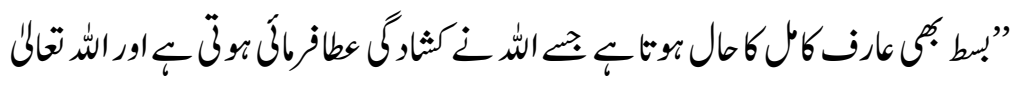
rree

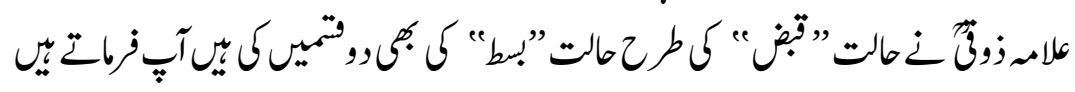


[r $\angle]$

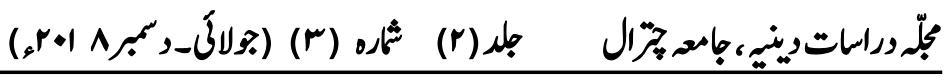

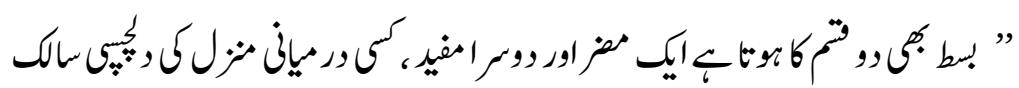

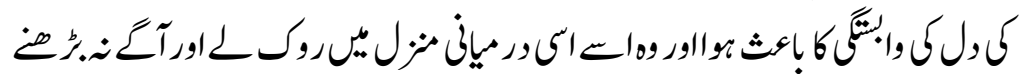

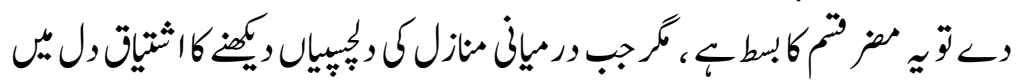

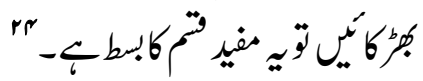

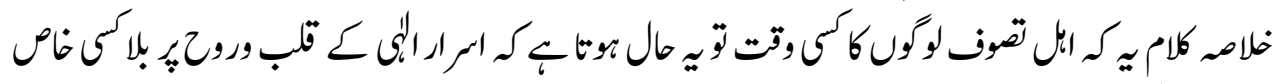

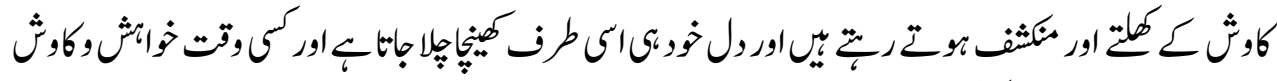

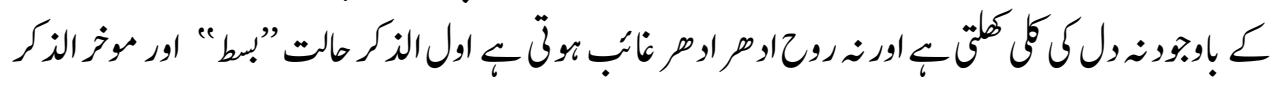

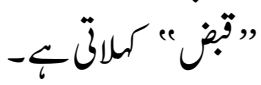

(r)

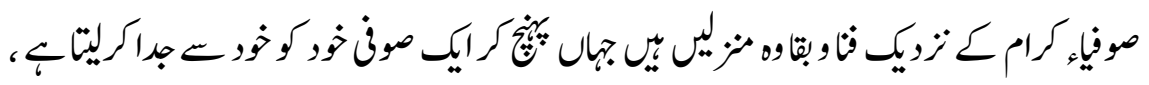

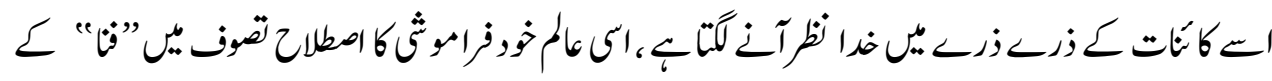

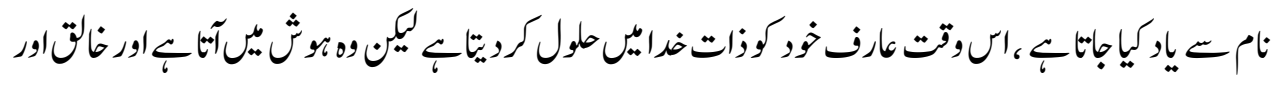

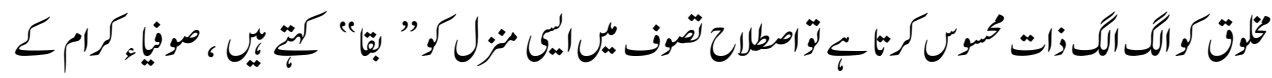

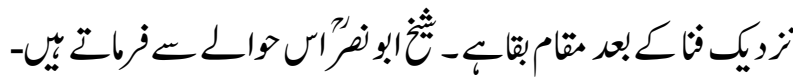

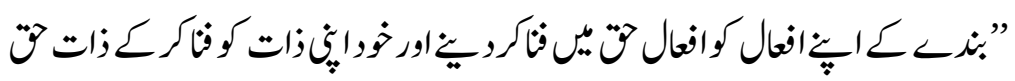

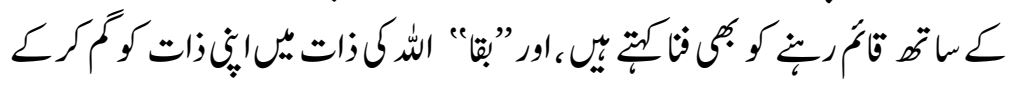

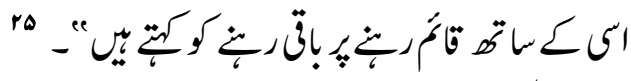

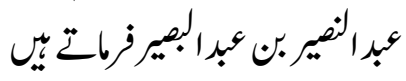

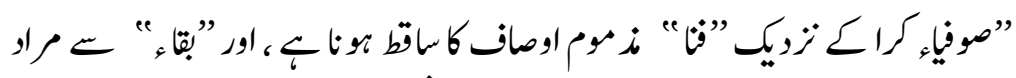

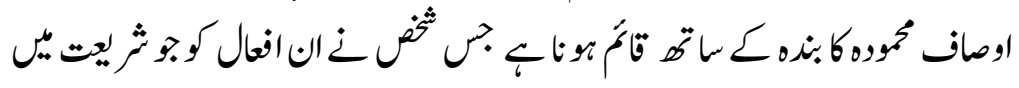

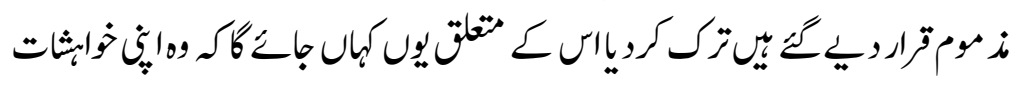

r4 -

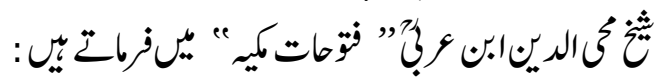

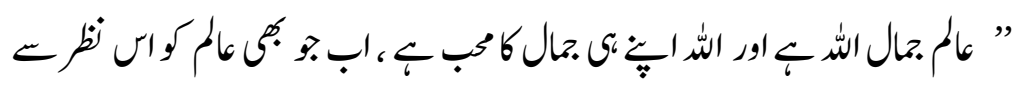

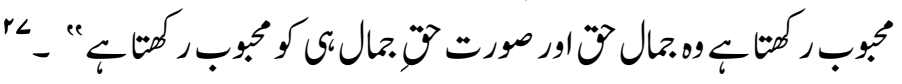

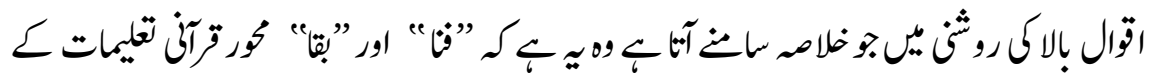

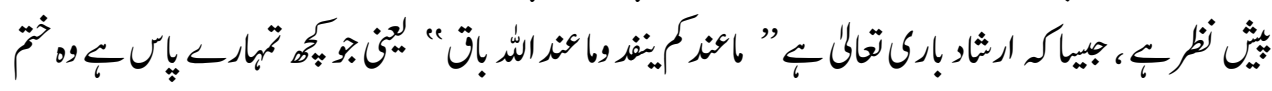


[mA]

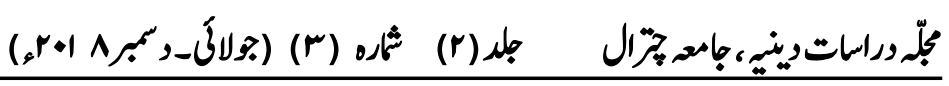

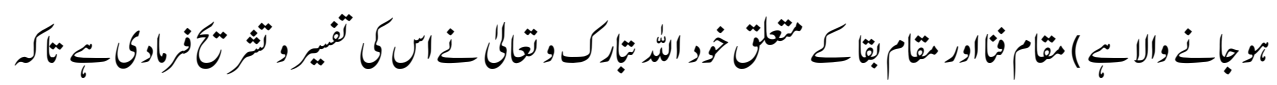

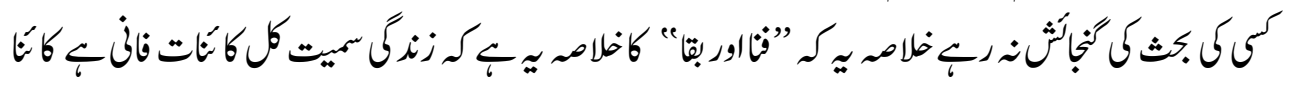

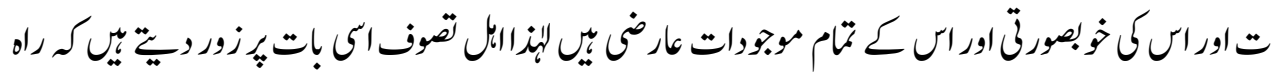

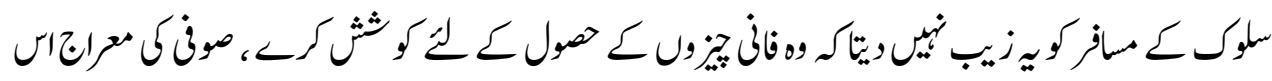

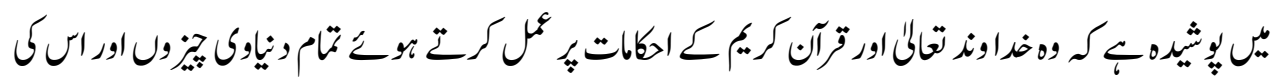

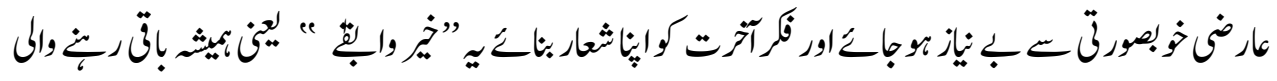

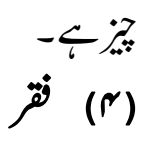

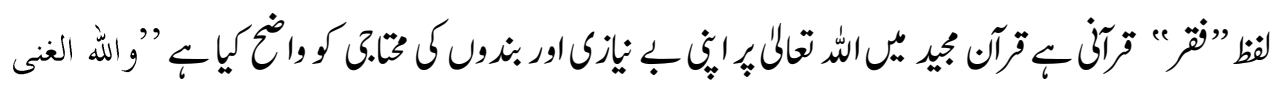

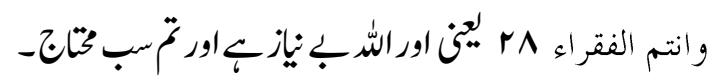

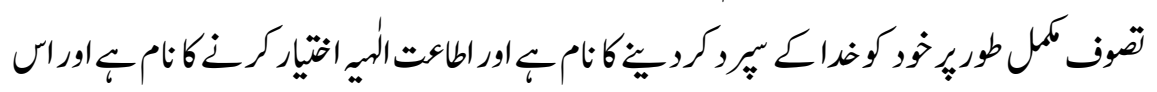

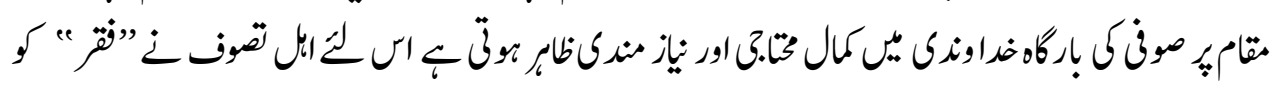

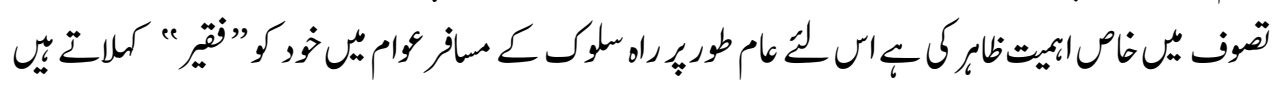

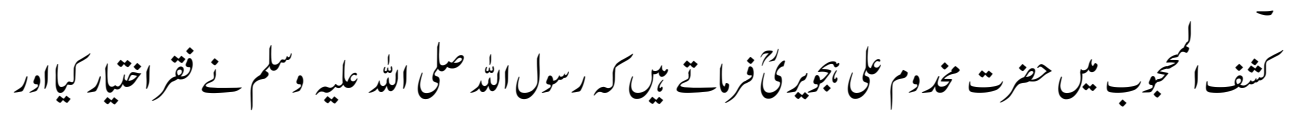

زرا:

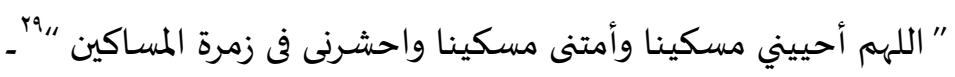

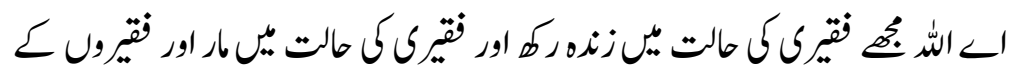

زمرهي ميراحثر فراس

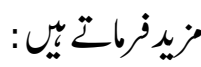

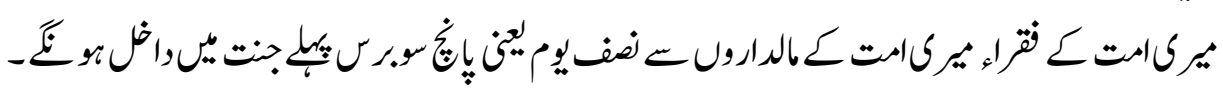

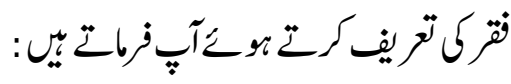

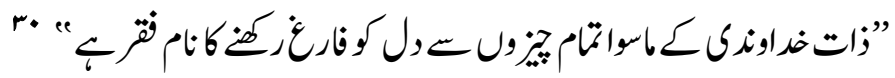

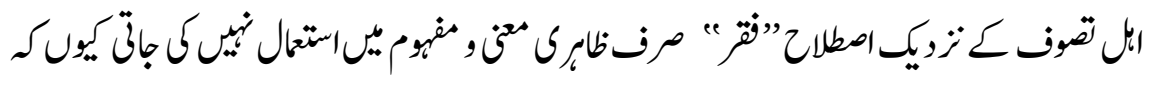

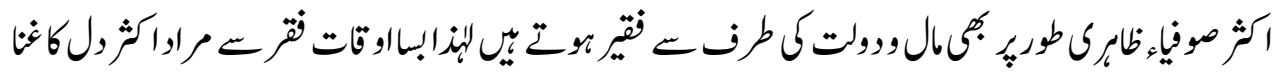

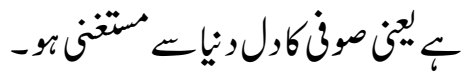


[rq]

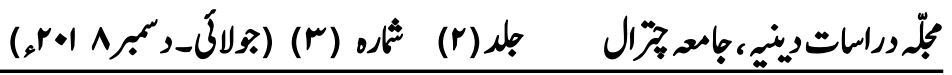

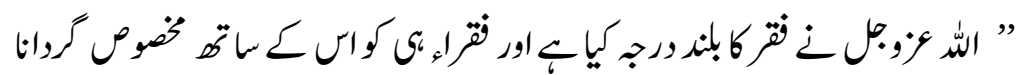

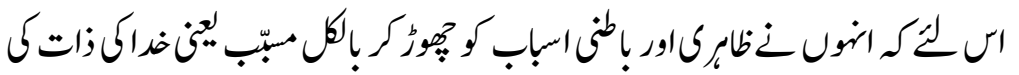

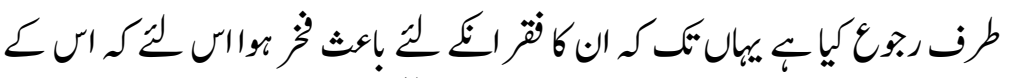

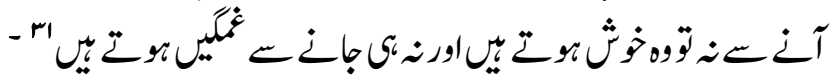

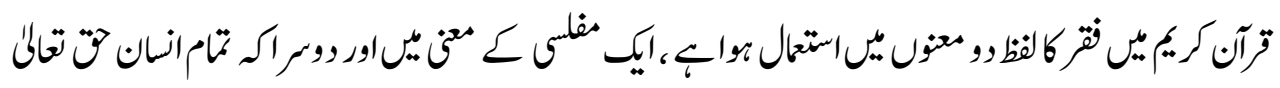

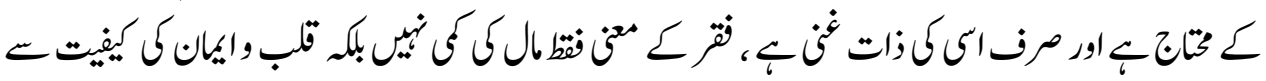

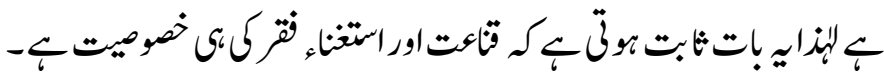

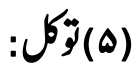

معن

"الثقة بالله والإيقان بأنّ قضاءه ماض، واتباع نبيه في السعي فيما لا بد بد

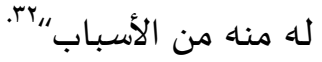

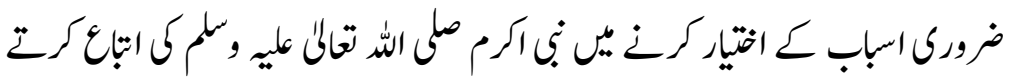

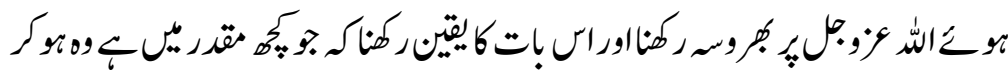

$-6$

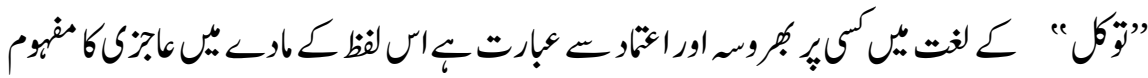

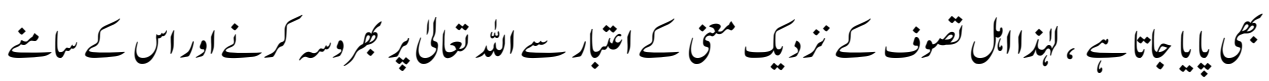

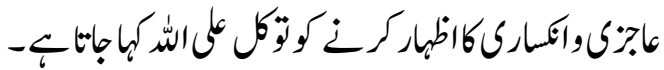

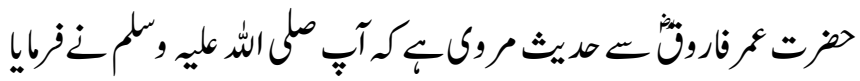

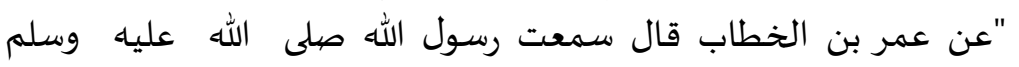

يقول لو أنكم تتوكلون على الله حق توكله لرزقكم كما يرزق الطير تغدو

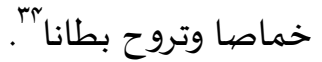

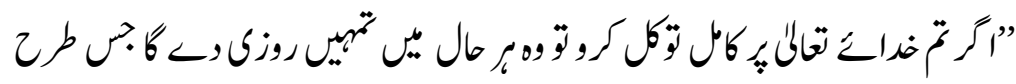

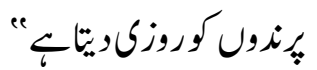

حزت ابرانيم

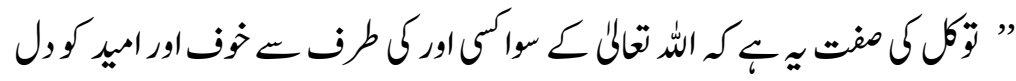

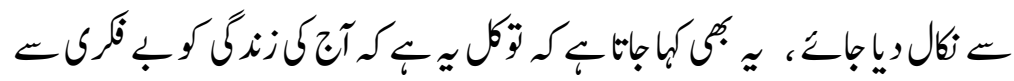

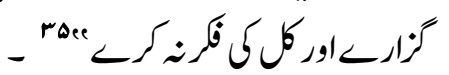


[ब•]

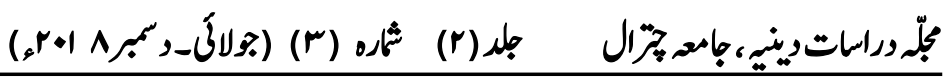

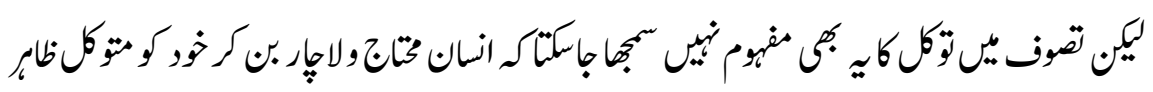

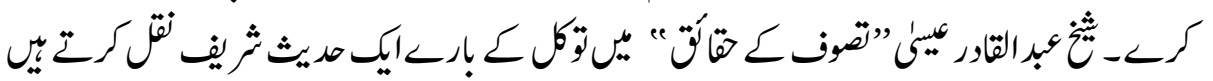

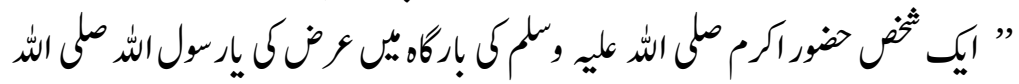

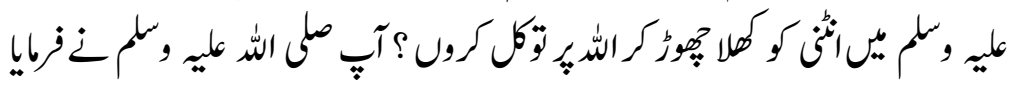

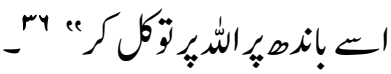

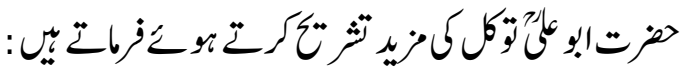

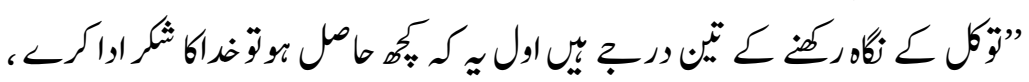

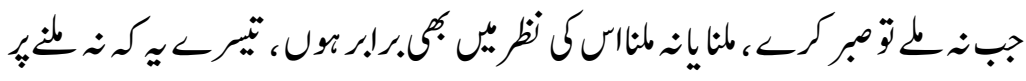

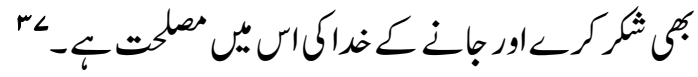

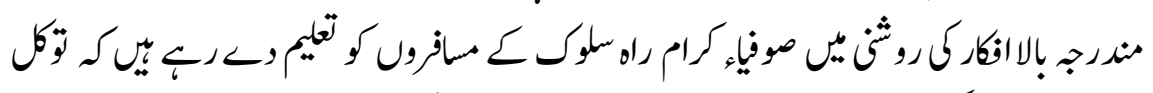

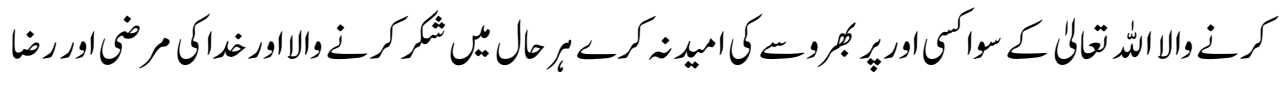

: بن

وبه: (Y)

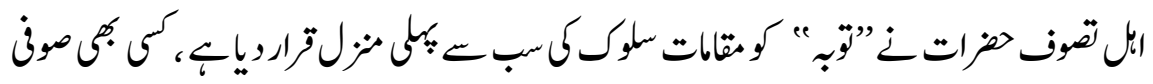

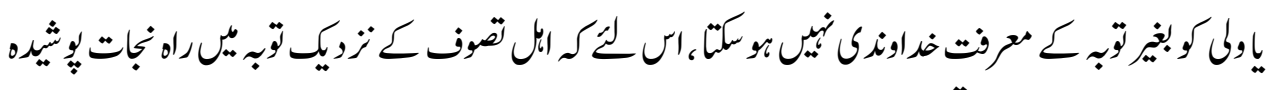

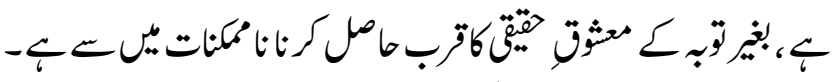

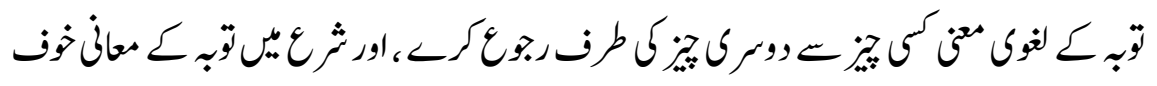

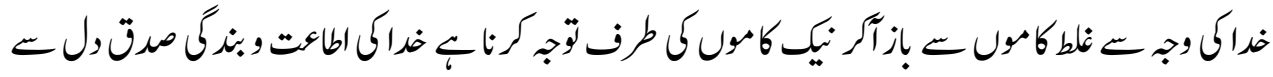

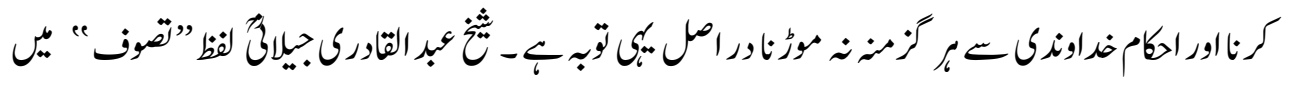

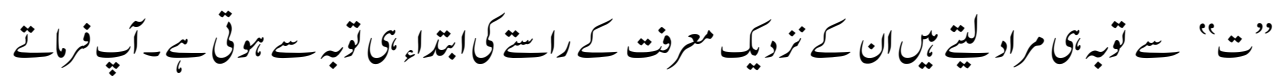

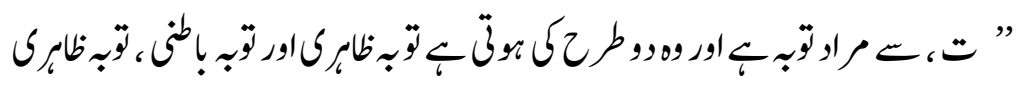

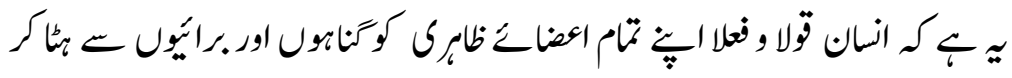

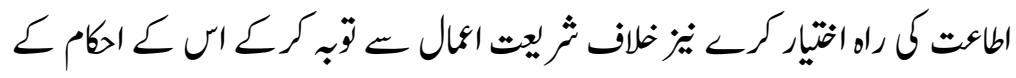

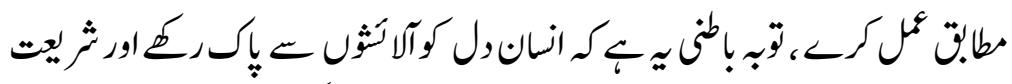

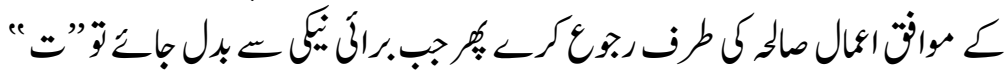

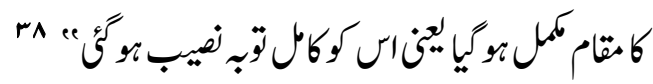


[Q1]

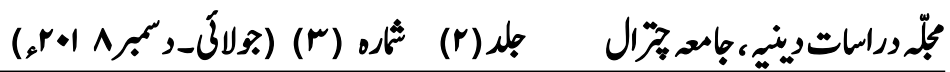

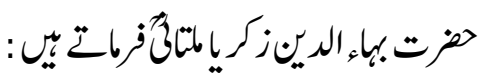

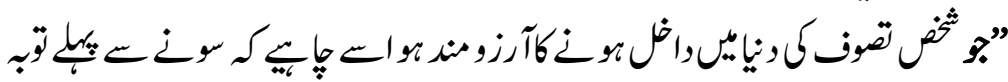

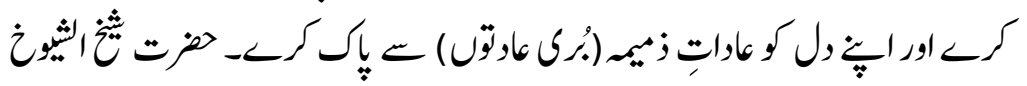

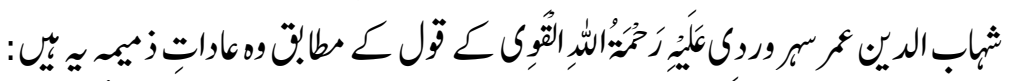

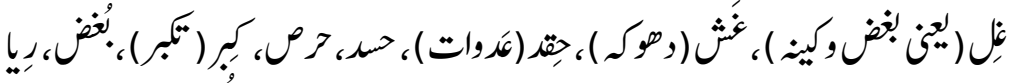

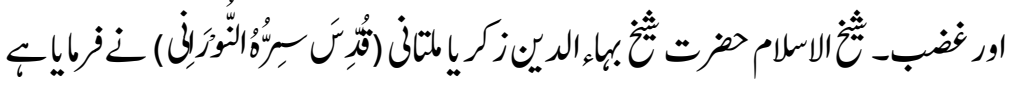

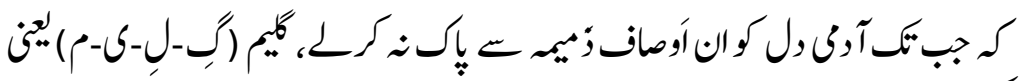

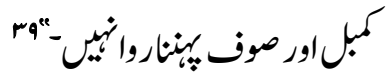

انابت

(<)

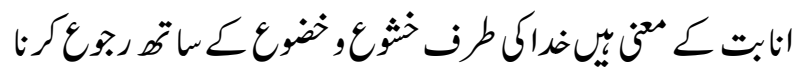

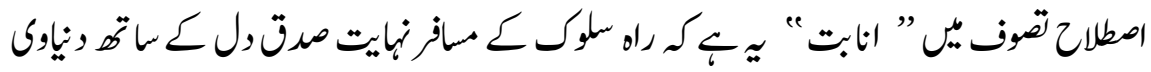

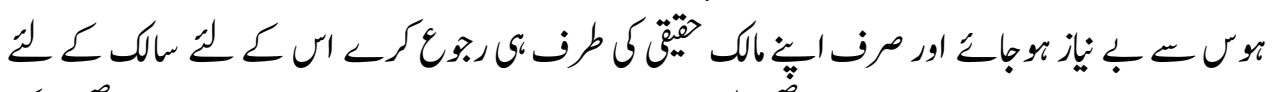

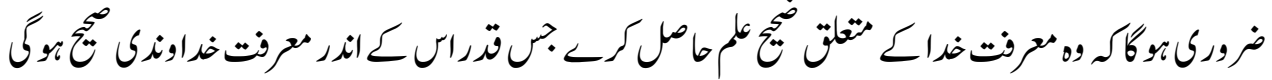

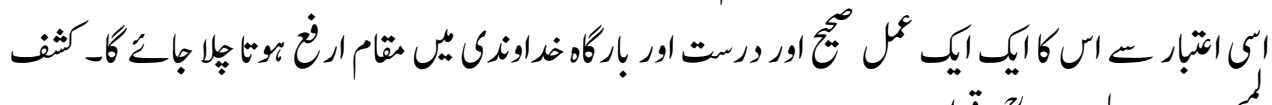

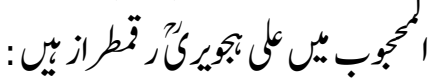

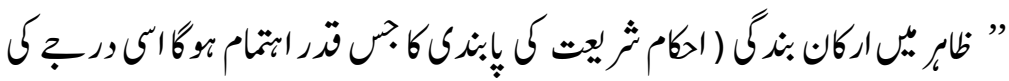

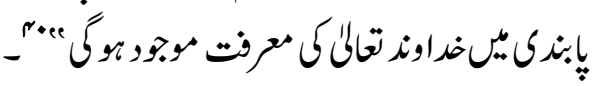

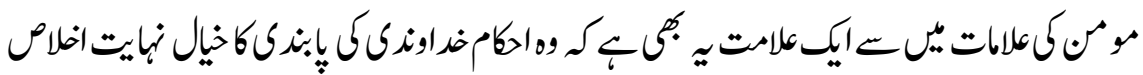

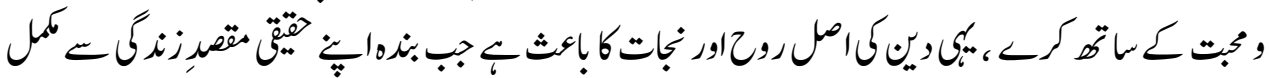

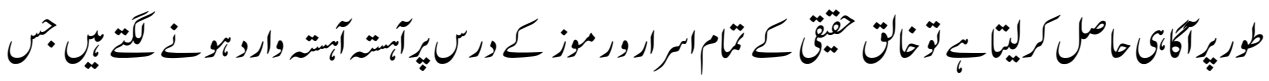

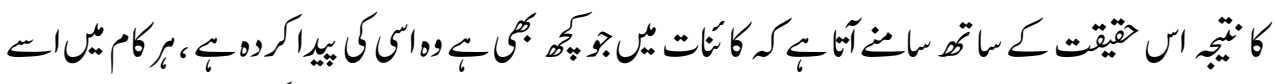

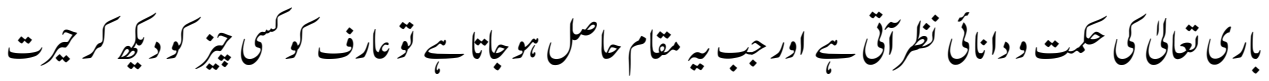

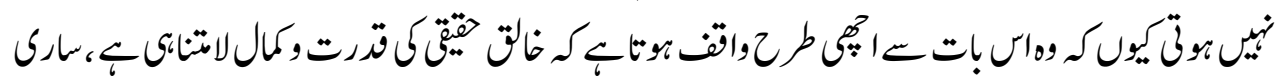

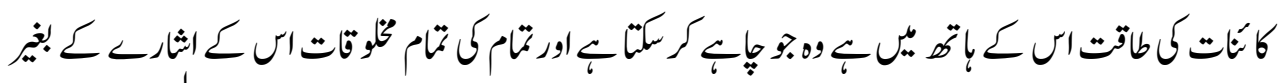

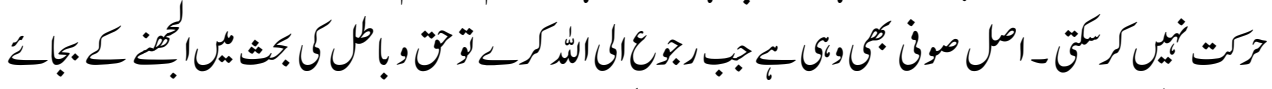

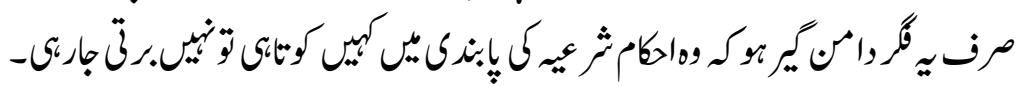


$[\Delta r]$

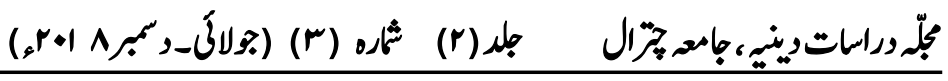

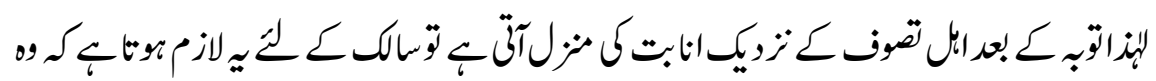

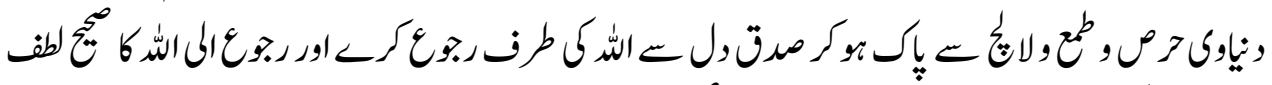

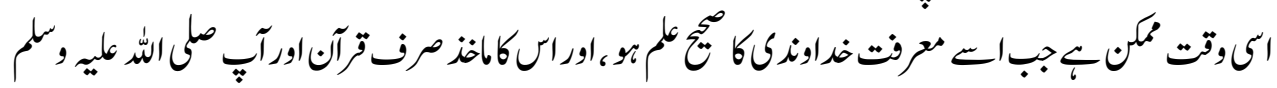

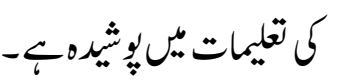

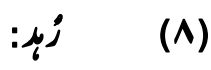

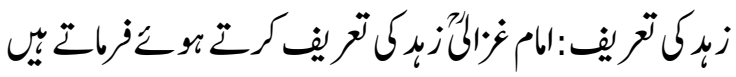

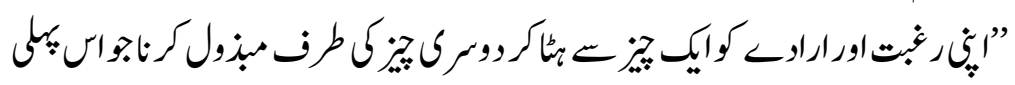

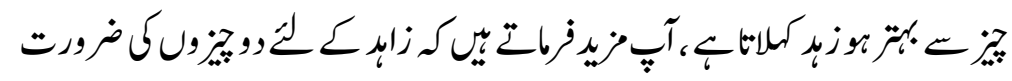

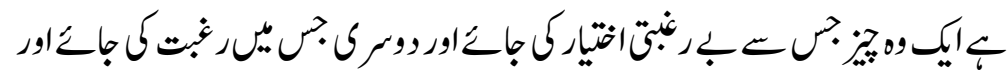

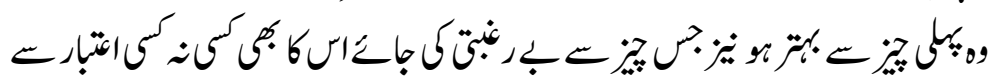

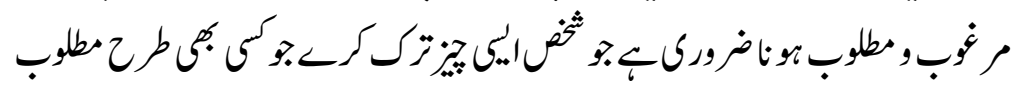

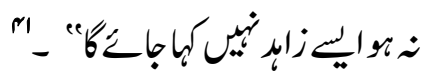

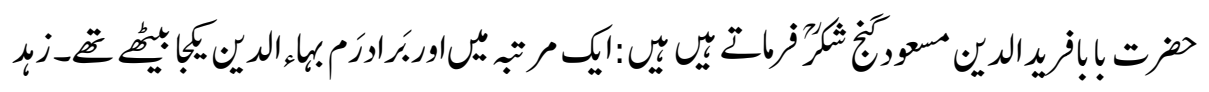

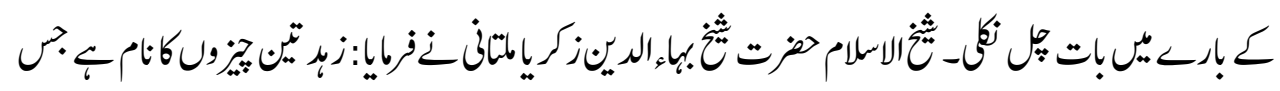

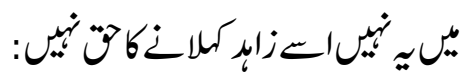

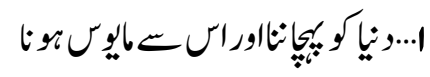

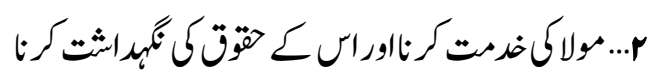

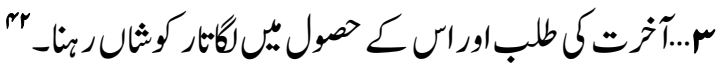

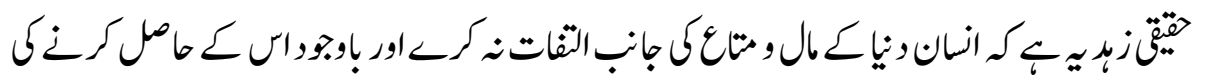

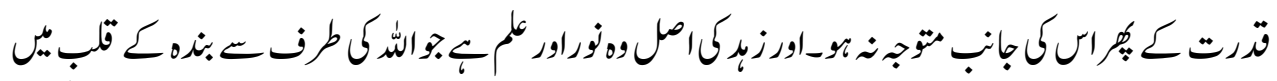

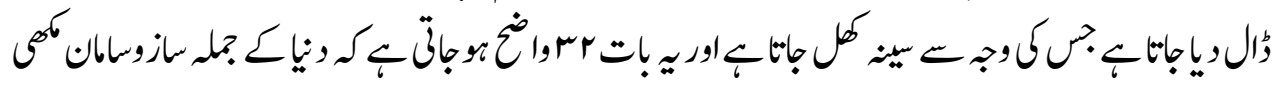

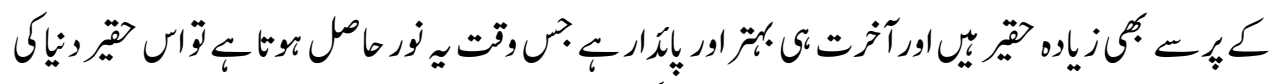

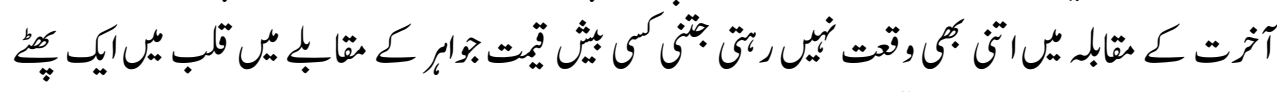

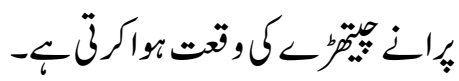


$[\Delta r]$

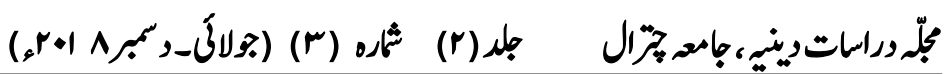

رضا:

(9)

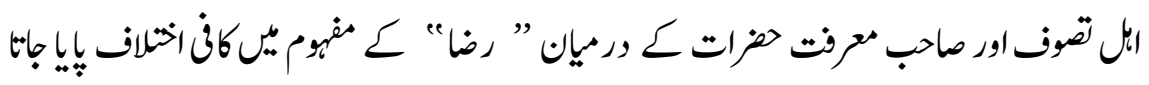

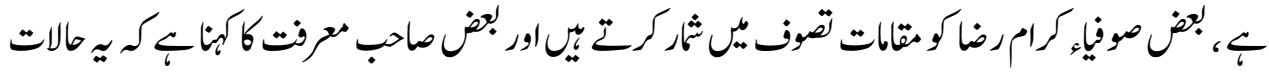

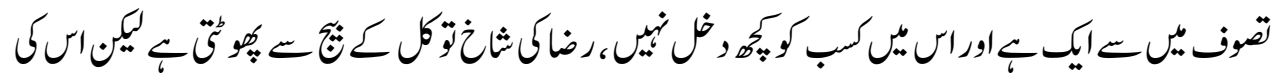

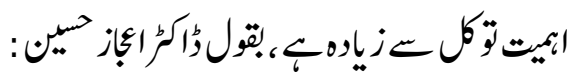

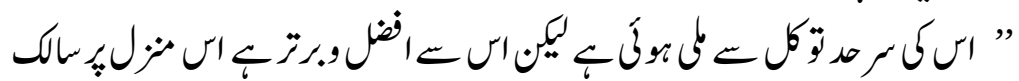

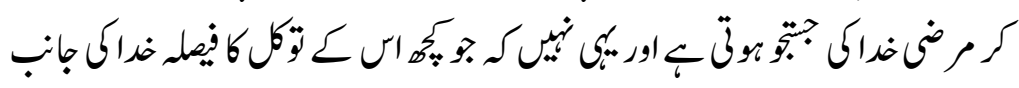

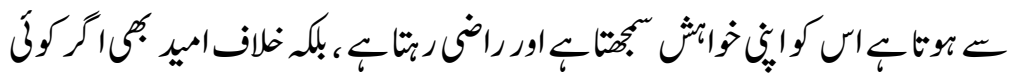

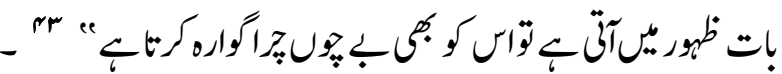

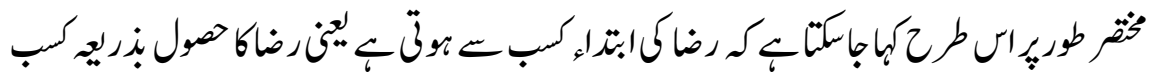

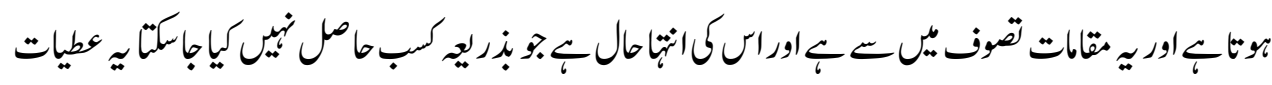

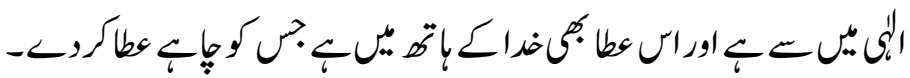

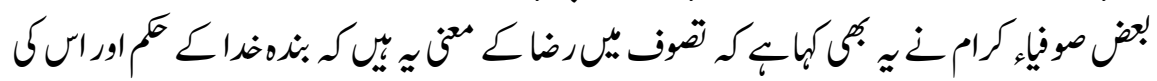

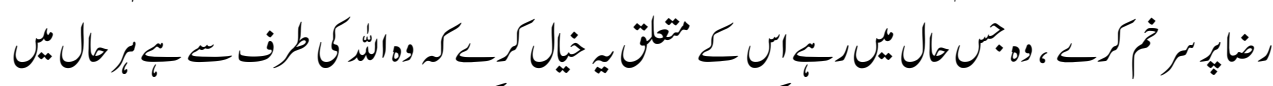

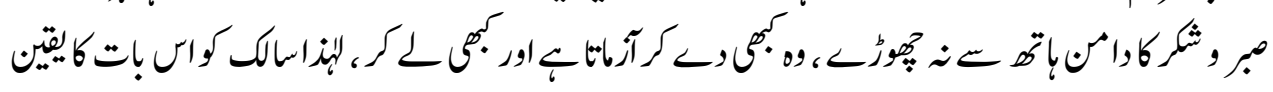

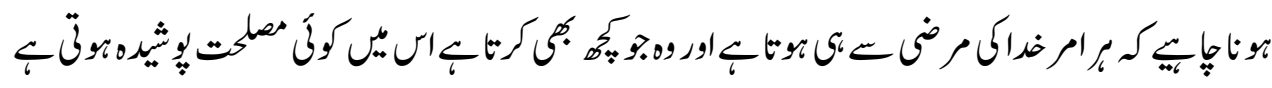

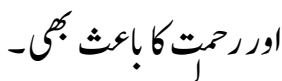

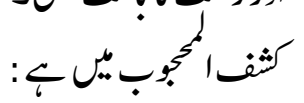

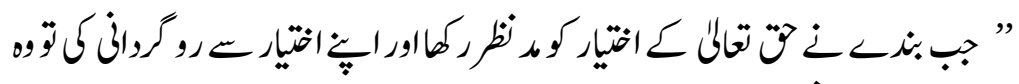

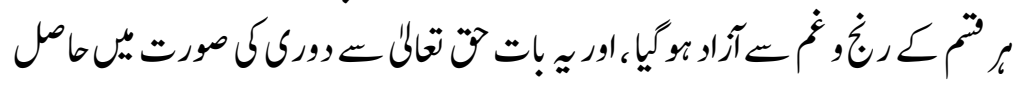

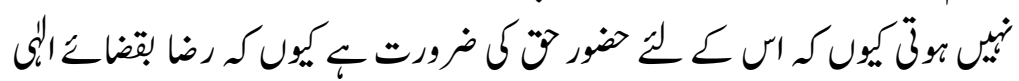

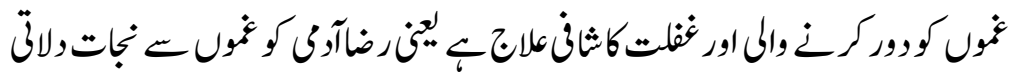

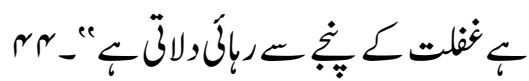

:

(1•)

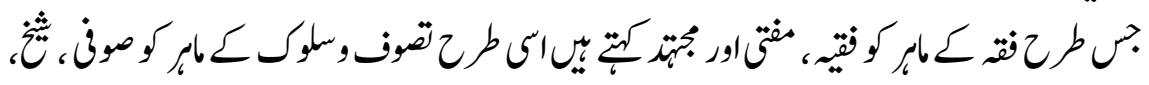

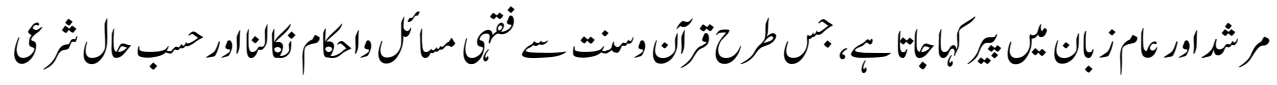

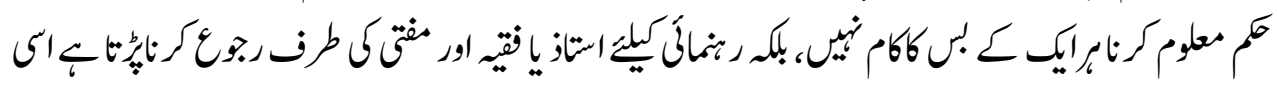


$[\Delta r]$

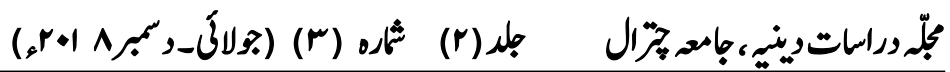

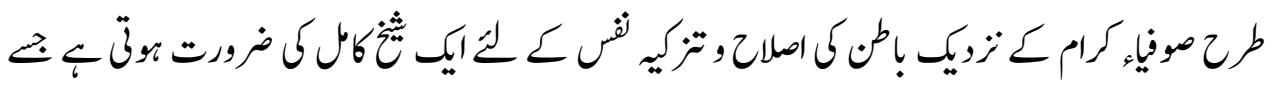

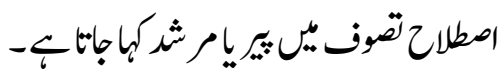

(II) بيتت:

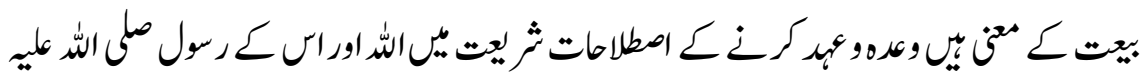

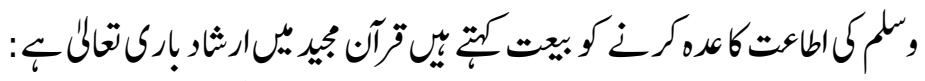

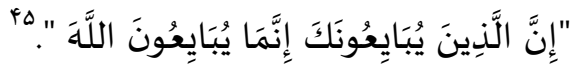

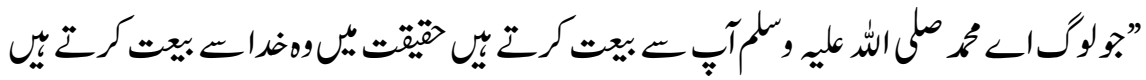

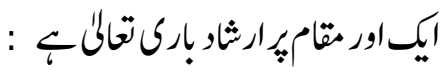

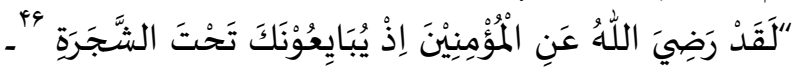

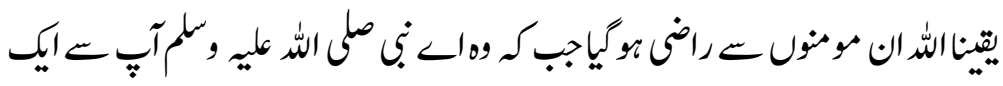

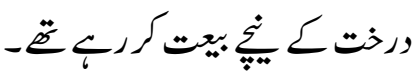

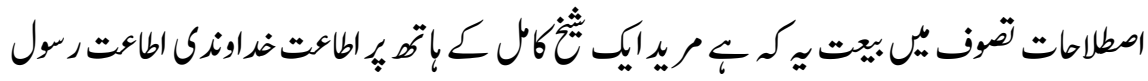

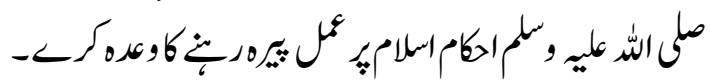

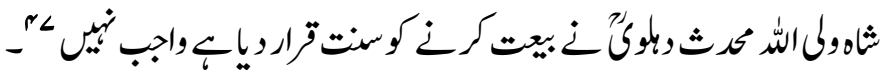

خاصم :

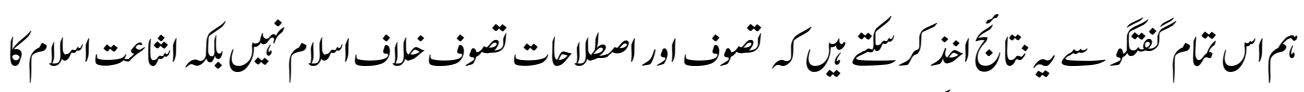

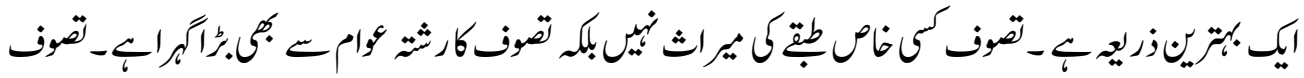

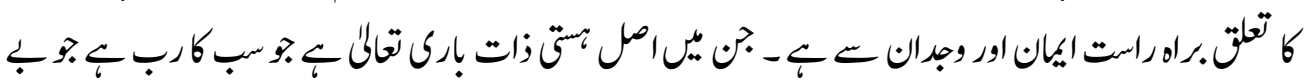

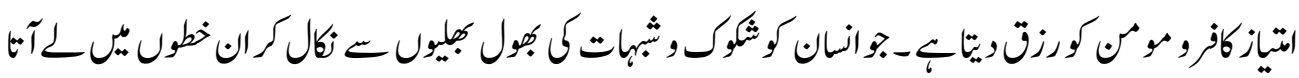

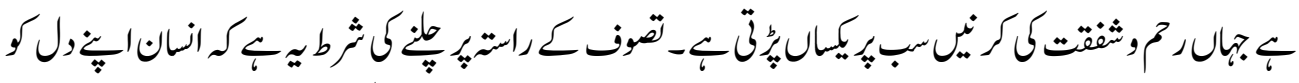

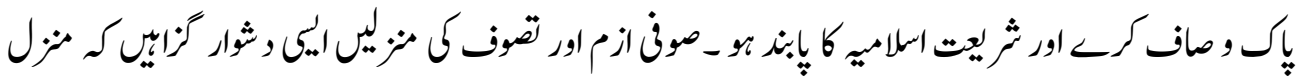

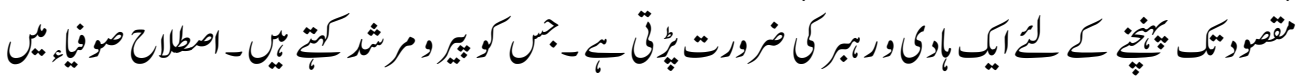

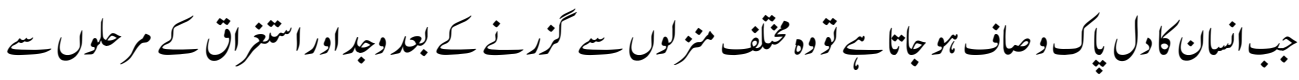

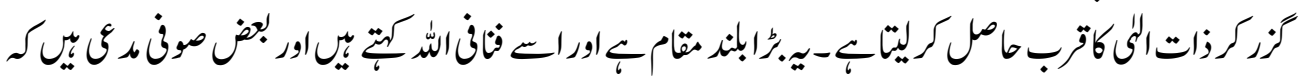

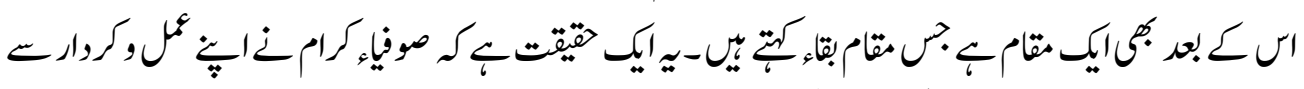

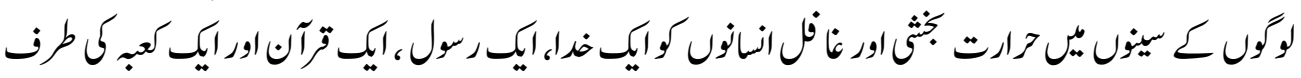

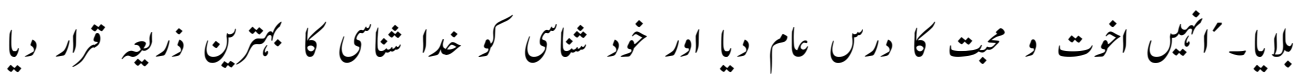




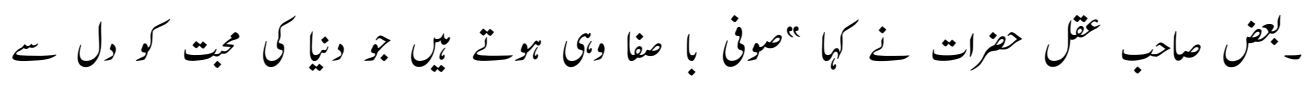

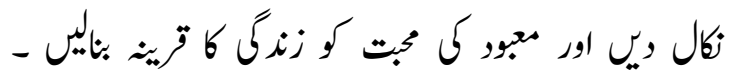

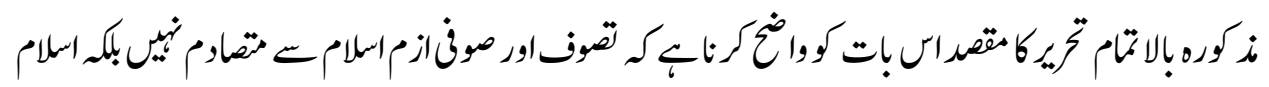

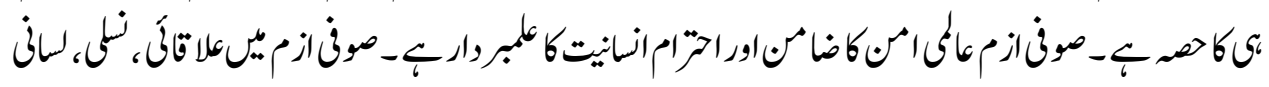

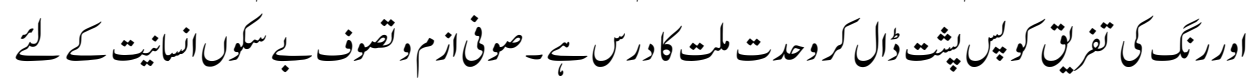

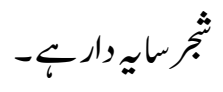

حاثَ وحال جات

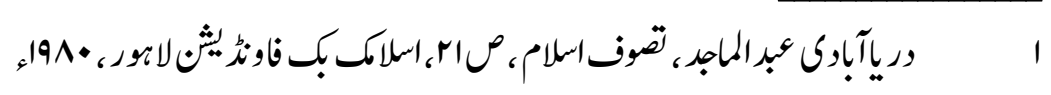

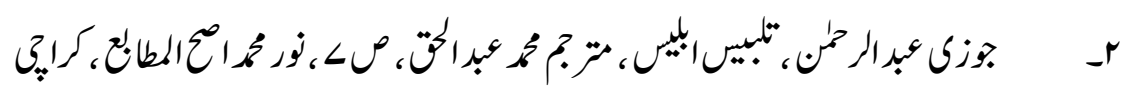

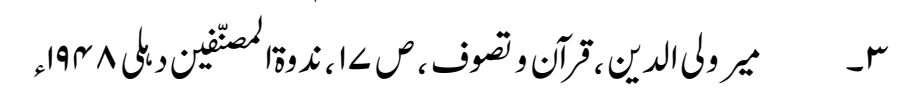

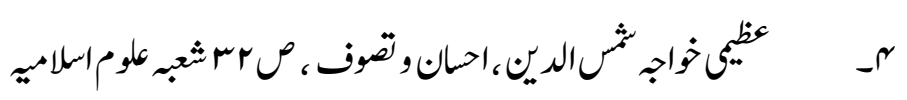

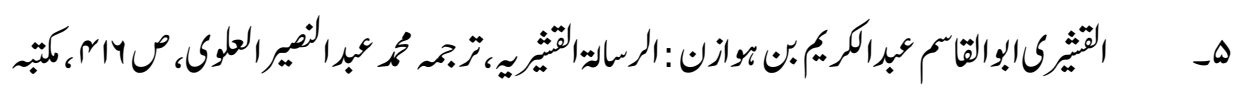

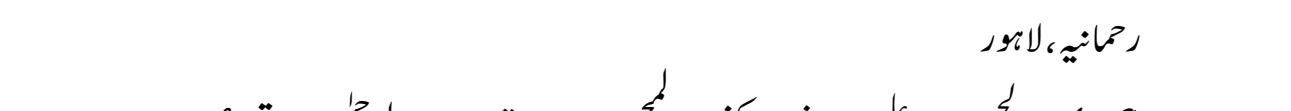

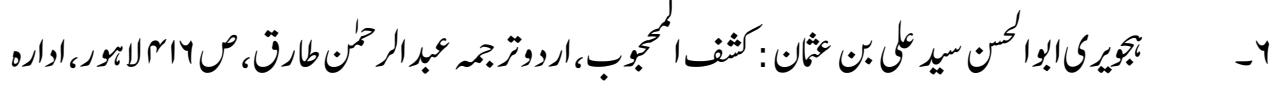

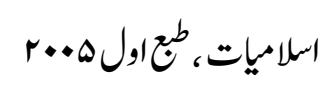

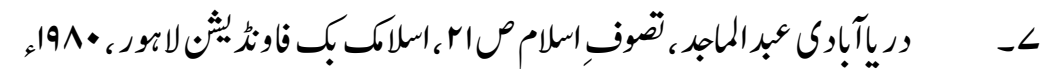

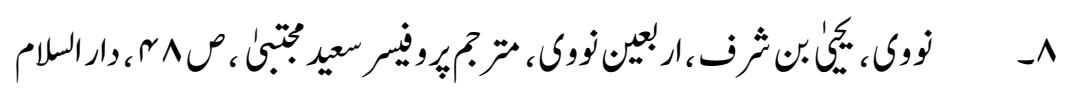

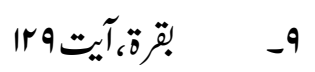

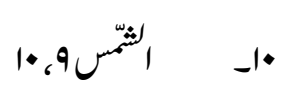

- 11

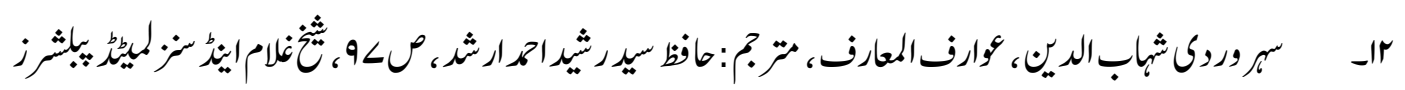


[QY]

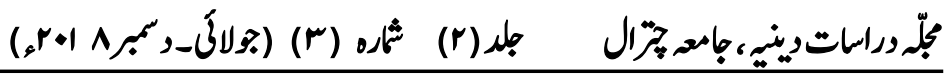

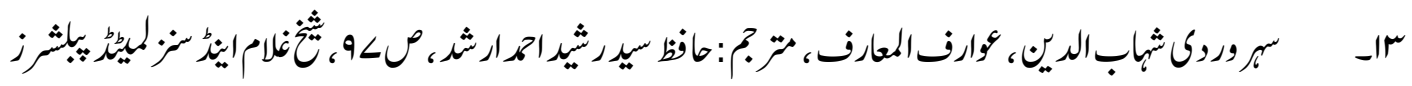

$199 \pi$

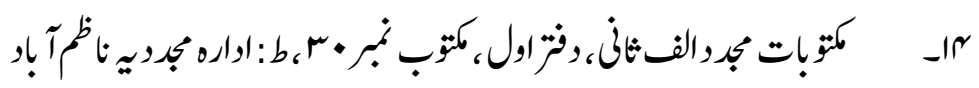

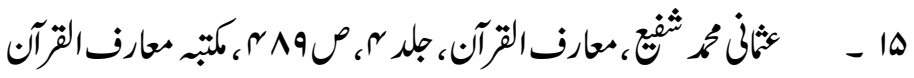

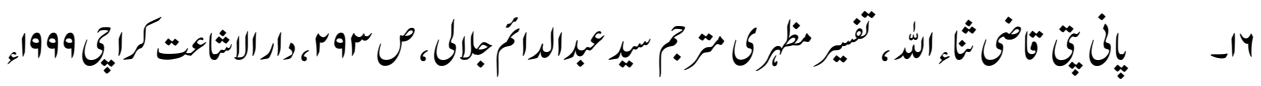

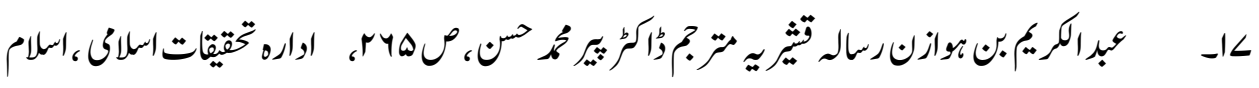

آו

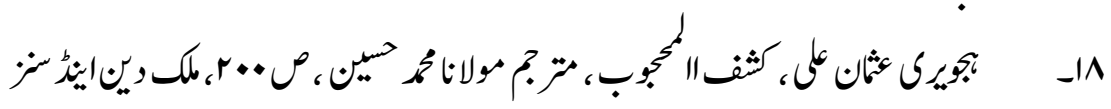

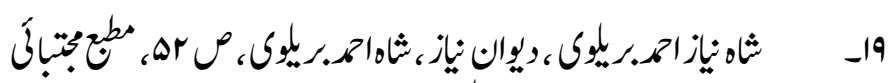

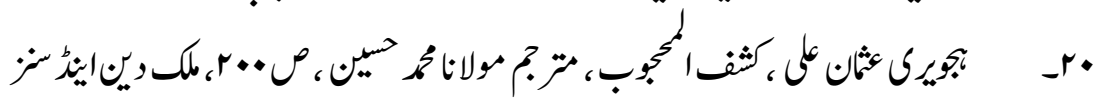

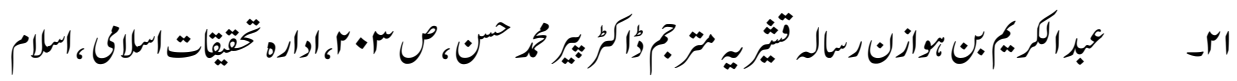

آب

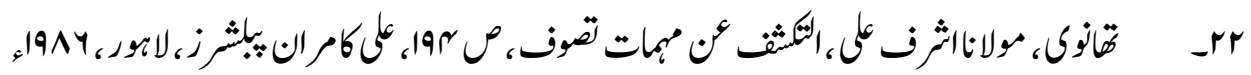

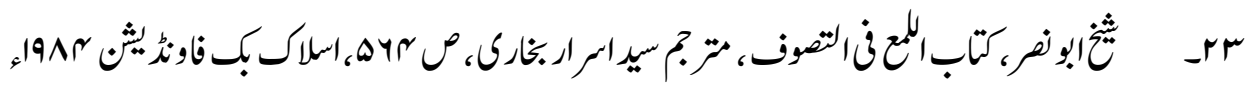

rrr

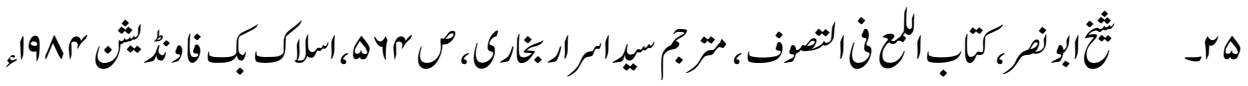

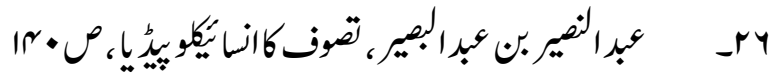

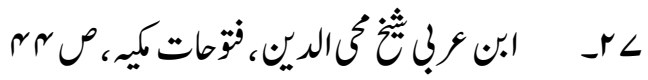

$r \Lambda: R$

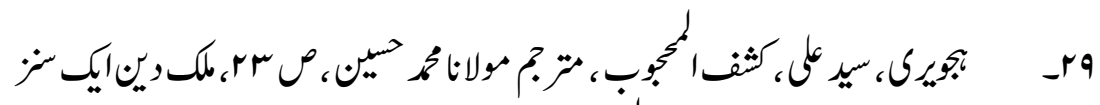

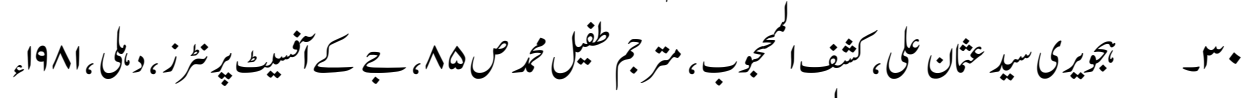

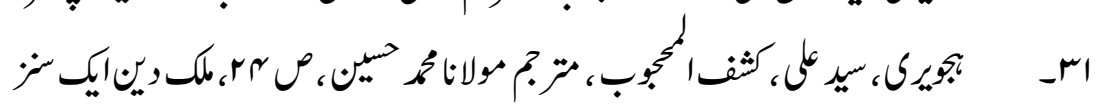

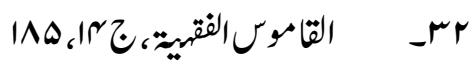


$[\bowtie<]$

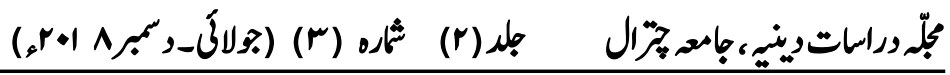

$$
\text { r }
$$

rrr

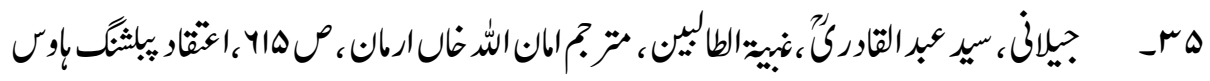

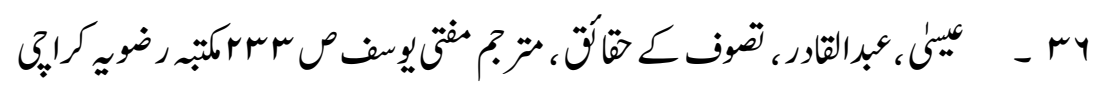

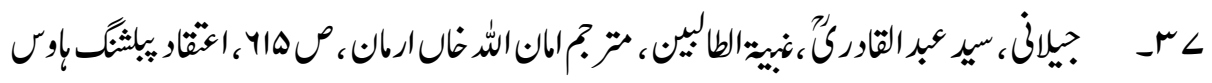

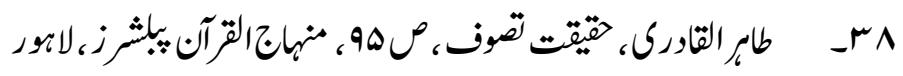

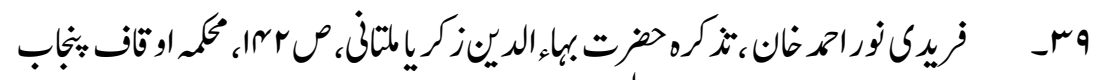

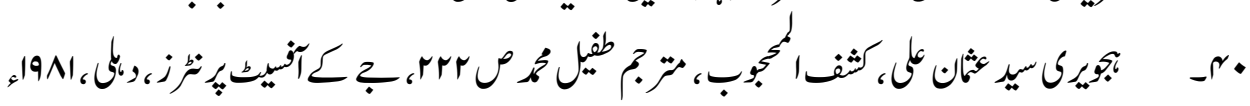

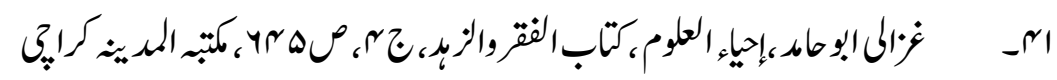
rre rre rr

لانور

$1+: \ddot{i} \quad r \Delta$

$1 \Lambda: \ddot{i} \quad r Y$

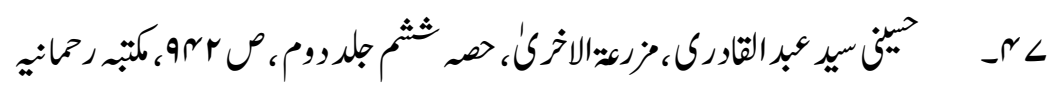

